\title{
Central control of brown adipose tissue thermogenesis
}

\section{Shaun F. Morrison*, Christopher J. Madden and Domenico Tupone}

Department of Neurological Surgery, Oregon Health and Science University, Portland, OR, USA

\section{Edited by:}

Patrick Seale, University of

Pennsylvania, USA

\section{Reviewed by:}

Ralf Jockers, University of Paris, France

Patrick Seale, University of

Pennsylvania, USA

*Correspondence:

Shaun F. Morrison, Neurological

Surgery, Oregon Health and Science University, 3181 South West Sam Jackson Park Road, Portland, OR 97239, USA.

e-mail:morrisos@ohsu.edu

Thermogenesis, the production of heat energy, is an essential component of the homeostatic repertoire to maintain body temperature during the challenge of low environmental temperature and plays a key role in elevating body temperature during the febrile response to infection. Mitochondrial oxidation in brown adipose tissue (BAT) is a significant source of neurally regulated metabolic heat production in many species from mouse to man. BAT thermogenesis is regulated by neural networks in the central nervous system which responds to feedforward afferent signals from cutaneous and core body thermoreceptors and to feedback signals from brain thermosensitive neurons to activate BAT sympathetic nerve activity. This review summarizes the research leading to a model of the feedforward reflex pathway through which environmental cold stimulates BAT thermogenesis and includes the influence on this thermoregulatory network of the pyrogenic mediator, prostaglandin $E_{2}$, to increase body temperature during fever. The cold thermal afferent circuit from cutaneous thermal receptors, through second-order thermosensory neurons in the dorsal horn of the spinal cord ascends to activate neurons in the lateral parabrachial nucleus which drive GABAergic interneurons in the preoptic area (POA) to inhibit warm-sensitive, inhibitory output neurons of the POA. The resulting disinhibition of BAT thermogenesis-promoting neurons in the dorsomedial hypothalamus activates BAT sympathetic premotor neurons in the rostral ventromedial medulla, including the rostral raphe pallidus, which provide excitatory, and possibly disinhibitory, inputs to spinal sympathetic circuits to drive BAT thermogenesis. Other recently recognized central sites influencing BAT thermogenesis and energy expenditure are also described.

Keywords: brown adipose tissue, thermogenesis, thermoregulation, sympathetic nerve activity, preoptic hypothalamus, fever, rostral raphe pallidus, rostral ventromedial medulla

\section{INTRODUCTION}

Thermogenesis, the production of heat energy, is an essential component of the homeostatic repertoire to maintain body temperature during the challenge of low environmental temperature. The heat generated during pyrogen-stimulated thermogenesis in brown adipose tissue (BAT) also contributes to fever, a controlled elevation in body temperature that reduces pathogen viability and stimulates immune cell responses. Since energy consumption during thermogenesis can involve oxidation of lipid fuel molecules, regulation of thermogenesis in response to metabolic signals can also contribute to energy balance and regulation of body adipose stores. Indeed, there is increasing interest in devising pharmacological approaches to maintaining the activation of BAT energy consumption as a metabolic furnace to burn the excess calories stored in the white adipose tissue of the obese (Clapham, 2011).

Thermogenesis can occur to a greater or lesser extent in most tissues, since heat generation is a by-product of the inefficiency of mitochondrial ATP production and of ATP utilization. However, CNS thermoregulatory networks can stimulate thermogenesis in response to a cold environment, to a fall in core body temperature or to the presence of pyrogenic cytokines primarily in three tissues: BAT, skeletal muscle, and the heart. In contrast to the indirect nature of shivering thermogenesis in skeletal muscles that are normally used to produce movement and posture, "non-shivering" thermogenesis in BAT is the specific metabolic function of this tissue and is accomplished by the heat generating capacity of a significant facilitated proton leak across the extensive mitochondrial membranes of the brown adipocytes which occurs because of the high expression of uncoupling protein-1 (UCP1) in BAT mitochondria (Cannon and Nedergaard, 2004). The levels of BAT sympathetic nerve activity (SNA), of ganglion cell norepinephrine release and of $\beta 3$-adrenergic receptor binding to brown adipocytes determine the level of thermogenesis in BAT by regulating both the activity of lipases, such as hormone-sensitive lipase and adipose tissue triacylglycerol lipase, providing the immediate fuel molecules for BAT mitochondria and the level of expression of BAT mitochondrial UCP1 (Cannon and Nedergaard, 2004). Recently, alternatively activated, adipose tissue macrophages have also emerged as a significant source of norepinephrine for the cold-evoked stimulation of BAT thermogenesis (Nguyen et al., 2011).

Brown adipose tissue has developed as an essential thermoregulatory effector in cold defense in rodents and other small mammals (Golozoubova et al., 2006), including infant humans, whose large surface area to body mass ratio suggests that basal metabolism alone would yield insufficient heat to maintain body temperature in cold environments. Recent observations using PET to assess tissue glucose uptake (reviewed in Nedergaard et al., 2007) and 
UCP1 analysis of biopsied tissue have confirmed a remarkable amount of metabolically active, BAT in adult humans (Hany et al., 2002; Cypess et al., 2009; van Marken Lichtenbelt et al., 2009; Virtanen et al., 2009). The functional locations of BAT depots in adult humans bear an interesting similarity to those in rodents: a large BAT pad in the vicinity of the upper thorax, individual pads atop each of the paravertebral sympathetic ganglia, and in the vicinity of the adrenal gland and kidney. The stereotyped, but curious localization of BAT pads, exemplified, for instance, by those over each sympathetic ganglion, suggests that, in addition to the overall defense of core temperature in the cold, BAT may also serve an as yet undescribed function to maintain optimal neuronal and synaptic function in specific locations during situations in which the maintenance of core body temperature is challenged. Similar to its function in smaller mammals, adult human BAT activity (assessed by glucose uptake) is highly responsive to betaadrenergic agonists (Soderlund et al., 2007) and to environmental temperature (Christensen et al., 2006). In addition, the finding of significantly less metabolically active BAT in obese adult human (van Marken Lichtenbelt et al., 2009) has suggested a heretofore unrecognized interaction among BAT energy expenditure, overall energy homeostasis, and body weight.

This review describes our current understanding of the functional organization of the central neural pathways (Figure 1), including the core thermoregulatory network, regulating the sympathetic outflow to BAT and, in turn, BAT thermogenesis and energy expenditure.

\section{THERMOREGULATORY CONTROL OF BAT THERMOGENESIS}

The core thermoregulatory network in the central nervous system (Figure 1) comprises the fundamental pathways through which cutaneous and visceral cold and warm sensation and/or reductions or elevations in brain temperature elicit changes in thermoregulatory effector tissues to counter or protect against changes in the temperature of the brain and other critical organ tissues. As with other thermal effectors (reviewed in Morrison, 2011; Morrison and Blessing, 2011), the thermoregulatory control of BAT thermogenesis occurs through a circuit that includes the pathways transmitting ambient temperature signals from thermal receptors in the skin to the hypothalamic networks that receive and integrate them with brain temperature information to activate efferent pathways to the thermal effectors. Each of the synaptic integration sites in the core thermoregulatory pathway constitutes a potential site for the modulation of BAT thermogenesis by non-thermal signals.

The thermoregulatory control of BAT thermogenesis in response to environmental temperature constitutes a feedforward reflex or "central command" drive, in that the stimulus of a cold environment in contact with skin thermal receptors is not, itself, affected by the evoked thermogenic response, but rather, BAT thermogenesis is initiated to counter a "predicted" fall in body core temperature that would result from the exposure to the cold environment. In contrast, the control of BAT thermogenesis by temperature-sensitive neurons in the brain constitutes a negative feedback reflex in that the warm-sensitive, preoptic area (POA) neurons activated by the increases in brain temperature resulting from stimulated BAT thermogenesis act, in turn, to inhibit sympathetic outflow to BAT.

\section{CUTANEOUS THERMAL RECEPTOR AFFERENT PATHWAY Cutaneous thermoreception}

The thermoregulatory system initiates defensive thermoregulatory responses in response to changes in skin temperature before they affect body core temperature. In this way, exposure to a cold environment can leave core and brain temperatures unaffected or slightly increased (Lomax et al., 1964; Bratincsak and Palkovits, 2005). Such environmental temperature sensation is mediated through cutaneous thermoreceptors which are located in primary sensory nerve endings distributed in the skin. The molecular mechanisms of cutaneous thermoreception appear to reside in the transient receptor potential (TRP) family of cation channels. The strongest data are in support of the TRPM8 as the cutaneous cold receptor TRP channel: TRPM8 is activated by modest cooling ( $<27^{\circ} \mathrm{C}$; McKemy et al., 2002; Peier et al., 2002), TRPM8-deficient nerve fibers show profound loss of cold sensitivity and TRPM8deficient mice exhibit a reduced ability to avoid innocuous cold temperatures (Bautista et al., 2007; Colburn et al., 2007; Dhaka et al., 2007). In addition, TRPM8 is activated by menthol (McKemy et al., 2002; Peier et al., 2002) which evokes warm-seeking behavior as well as cold-defensive, physiological responses. TRPV3 and TRPV4 are warm-sensitive TRP channels that are activated by innocuous warm temperatures and are expressed in keratinocytes in skin epidermis. Compared to wild-type mice, mice lacking either TRPV3 or TRPV4 show altered behaviors in discriminating innocuous warm temperatures (Lee et al., 2005; Moqrich et al., 2005).

Intriguing effects on body temperature control and BAT thermogenesis have been reported for agonists and antagonists of TRPV1, a TRP channel that can be activated, in vitro, by a noxious range of heat $\left(>43^{\circ} \mathrm{C}\right)$, by protons $(\mathrm{pH} \leq 5.9)$ or by capsaicin (Tominaga et al., 1998). Peripheral or central administration of capsaicin induces hypothermia (Jancso-Gabor et al., 1970; Hori, 1984), an effect beneficial to people living in hot climates, but is ineffective in TRPV1-deficient mice (Caterina et al., 2000). Furthermore, administration of potent TRPV1 antagonists induces hyperthermia (Gavva et al., 2007) by both increasing metabolism and reducing heat loss from the body surface, but not by evoking warm-seeking behavior (Steiner et al., 2007) and this hyperthermic effect is likely exerted by antagonizing TRPV1 located within abdominal viscera (Steiner et al., 2007; Romanovsky et al., 2009). Therefore, tonic activation of peripheral TRPV1, effected by non-thermal stimuli at body temperatures below the threshold for TRPV1 activation, could provide afferent signals to lower body temperature (Romanovsky et al., 2009), however, TRPV1-deficient mice exhibit no obvious deficit in body temperature control (Szelenyi et al., 2004).

In addition to cutaneous thermoreception, thermoreceptive mechanisms exist in body core structures including the brain (e.g., neurons in the POA), spinal cord, and abdomen. The afferent fibers from cold and warm receptors in the abdominal viscera are included among the splanchnic and vagus nerve afferent fibers and their responses to temperature changes are similar to those of cutaneous thermoreceptors (Riedel, 1976; Gupta et al., 1979). Temperature changes in the spinal cord can affect the activity of thermoregulatory neurons in more rostral areas of the brain 
(Guieu and Hardy, 1970). TRP channels that are located in the central endings of primary somatosensory fibers in the spinal dorsal horn (Tominaga et al., 1998; Bautista et al., 2007) may sense spinal temperature and could underlie an integration of spinal thermal signals with cutaneous thermal signals at the spinal cord level. Thus, rather than responding directly to changes in environmental temperature, core body thermosensation could play a role (a) in setting the basal tone of thermoregulatory effector efferents

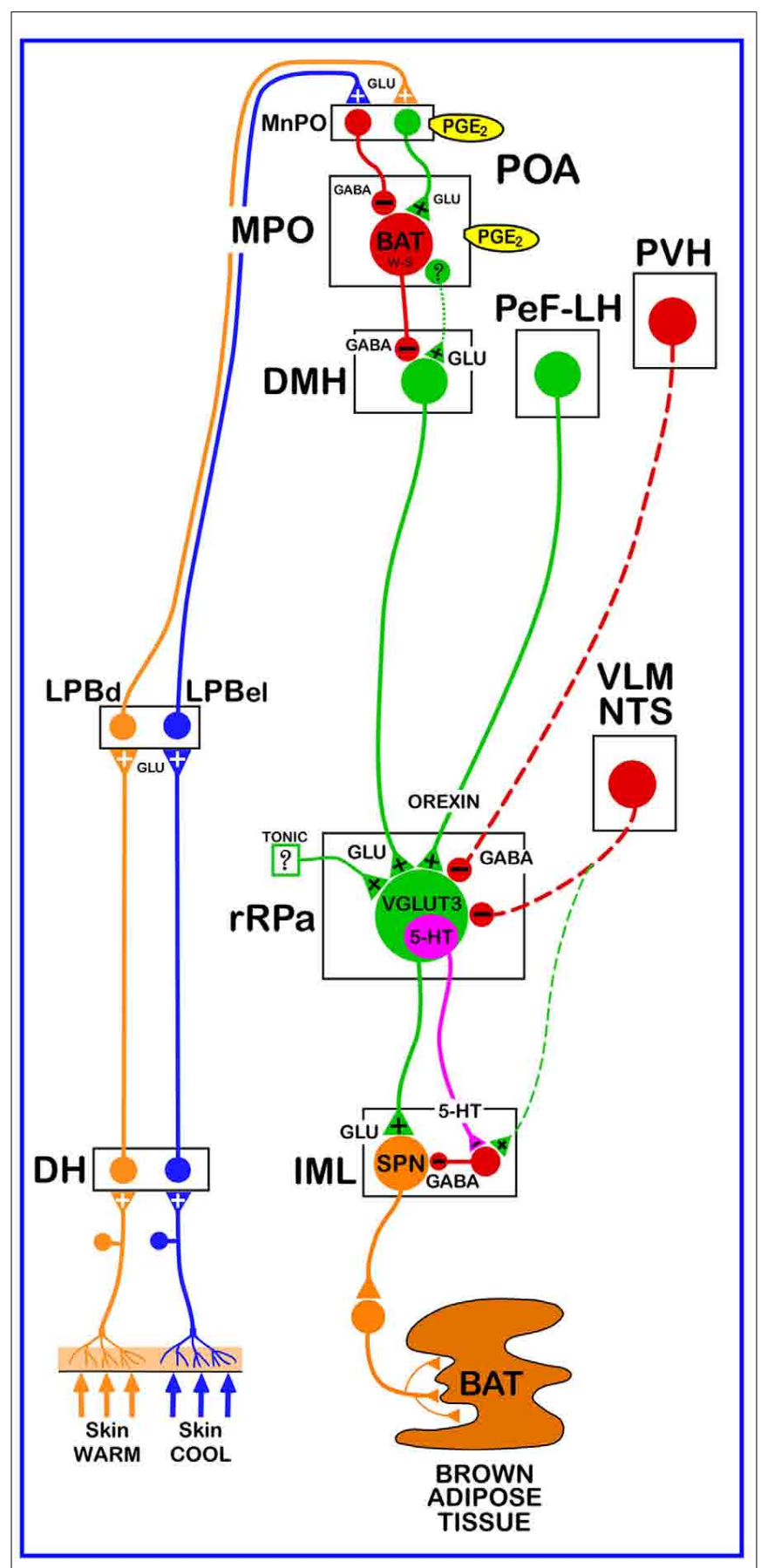

FIGURE 1 | Continued including BAT thermogenesis, (b) in enhancing thermoregulatory responses in situations of extreme thermal environments when the feedforward thermoregulatory responses driven by changes in skin temperature have proven inadequate to prevent changes in brain or body core temperature, and (c) in responding to challenges to thermal homeostasis involving shifts in internal body temperature brought about by changes in metabolism (e.g., exercise, hypoglycemia, hypoxia, etc.) or by changes in internal temperature (e.g., intake of cold fluids, hemorrhage, etc.).

\section{Dorsal horn}

Primary thermal somatosensory fibers deliver thermal information to lamina I neurons in the spinal (or trigeminal) dorsal horn (Craig, 2002; Figure 1). Craig and colleagues have described thermoreceptor-specific cells responding linearly to graded, innocuous cooling or warming stimuli, and not being activated further in the noxious temperature range (Andrew and Craig, 2001; Craig et al., 2001). The spinothalamocortical pathway, in which second-order thermosensory neurons in lamina I ascend to synapse on thalamic neurons that, in turn, project to the primary somatosensory cortex, is responsible for conscious

FIGURE 1 | Schematic of the proposed neuroanatomical and neurotransmitter model for the core thermoregulatory network and other CNS sites controlling brown adipose tissue (BAT)

thermogenesis. Cool and warm cutaneous thermal sensory receptors transmit signals to respective primary sensory neurons in the dorsal root ganglia which relay this thermal information to second-order thermal sensory neurons in the dorsal horn $(\mathrm{DH})$. Cool sensory $\mathrm{DH}$ neurons glutamatergically activate third-order sensory neurons in the external lateral subnucleus of the lateral parabrachial nucleus (LPBel), while warm sensory $\mathrm{DH}$ neurons project to third-order sensory neurons in the dorsal subnucleus of the lateral parabrachial nucleus (LPBd). Thermosensory signals for thermoregulatory responses are transmitted from the LPB to the preoptic area (POA) where GABAergic interneurons in the median preoptic (MnPO) subnucleus are activated by glutamatergic inputs from cool-activated neurons in LPBel and inhibit a BAT-regulating population of warm-sensitive (W-S) neurons in the medial preoptic (MPO) subnucleus. In contrast, glutamatergic interneurons in the MnPO, postulated to be excited by glutamatergic inputs from warm-activated neurons in LPBd, excite W-S neurons in MPO. Prostaglandin (PG) $E_{2}$ binds to EP3 receptors to inhibit the activity of W-S neurons in the POA. Preoptic W-S neurons providing thermoregulatory control of BAT thermogenesis inhibit BAT sympathoexcitatory neurons in the dorsomedial hypothalamus (DMH) which, when disinhibited during skin cooling, excite BAT sympathetic premotor neurons in the rostral ventromedial medulla, including the rostral raphe pallidus ( $\mathrm{rRPa}$ ), that project to BAT sympathetic preganglionic neurons (SPN) in the spinal intermediolateral nucleus (IML). Some BAT premotor neurons can release glutamate (GLU) to excite BAT SPNs and increase BAT sympathetic nerve activity, while others can release serotonin (5-HT) to interact with $5-\mathrm{HT}_{1 \mathrm{~A}}$ receptors, potentially on inhibitory interneurons in the IML, to increase the BAT sympathetic outflow and thermogenesis. Orexinergic neurons in the perifornical lateral hypothalamus (PeF-LH) project to the rRPa to increase the excitability of BAT sympathetic premotor neurons. Neurons in the paraventricular hypothalamic (PVH) nucleus exert an inhibitory influence on BAT thermogenesis, possibly via a GABAergic input to BAT sympathetic premotor neurons in $\mathrm{rRPa}$. Activation of neurons in the ventrolateral medulla (VLM) or in the nucleus of the solitary tract (NTS) produces an inhibition of BAT thermogenesis, potentially via a non-GABAergic input to $\mathrm{rRPa}$ or by activation of spinal inhibitory interneurons in the IML. VGLUT3, vesicular glutamate transporter 3. 
perception and discrimination of cutaneous temperature information (Craig et al., 1994; Craig, 2002). However, the spinothalamocortical pathway is not required to initiate or sustain involuntary thermoregulatory responses to environmental cold challenges, since thalamic lesions have no effect on sympathetic thermogenic responses to skin cooling (Nakamura and Morrison, 2008b). However, spinothalamic and trigeminothalamic lamina I neurons do send collateral axons to the lateral parabrachial nucleus (LPB) (Hylden et al., 1989; Li et al., 2006), which, as described below, transmits cutaneous thermosensory information to the core central thermoregulatory network controlling BAT thermogenesis. Another group of afferents likely to influence BAT thermogenesis (Niijima, 1999) arise from both BAT (Bartness et al., 2010) and white adipose tissue (Song et al., 2009). What these afferents sense, the pathways through which this information is relayed centrally and how these adipose afferent signals might influence BAT thermogenesis remain interesting questions.

\section{Lateral parabrachial nucleus}

Neurons in the external lateral subnucleus (LPBel) of the LPB and projecting to the median subnucleus (MnPO) of the POA are activated following cold exposure (Bratincsak and Palkovits, 2004; Nakamura and Morrison, 2008b), while those in the dorsal subnucleus (LPBd) are activated in response to skin warming (Bratincsak and Palkovits, 2004; Nakamura and Morrison, 2010). The discharge rate of single, MnPO-projecting LPBel neurons recorded in vivo increased markedly in response to skin cooling in a manner paralleling the skin cooling-evoked increases in BAT SNA (Nakamura and Morrison, 2008b). In contrast, single, MnPO-projecting LPBd neurons were excited by skin warming in parallel with the simultaneous inhibition of BAT SNA (Nakamura and Morrison, 2010). The critical role of LPB neurons in transmitting cutaneous, and possibly visceral, thermal sensory information to the hypothalamus to drive BAT thermogenic responses is demonstrated by the elimination of BAT responses to alterations in skin temperature following experimental inactivation of local neurons or blockade of local glutamate receptors in the LPB (Kobayashi and Osaka, 2003; Nakamura and Morrison, 2008b). Similarly, glutamate or other stimulations of LPBel or LPBd neurons can evoke BAT sympathetic and thermogenic responses that parallel those evoked during decreases or increases, respectively, in skin temperature (Nakamura and Morrison, 2008b, 2010). Thus, both cool and warm cutaneous thermosensory signals that are transmitted from spinal dorsal horn or trigeminal neurons to the POA by separate populations of LPB neurons (Figure 1) are essential for eliciting rapid responses in BAT thermogenesis to defend body temperature from a variety of thermal challenges. Although nociceptive inputs play only a minor role (Nakamura and Morrison, 2008b), we do not know what other signals are integrated with cutaneous cold afferent inputs to LPBel neurons in the feedforward pathway contributing to drive BAT thermogenesis during environmental cold challenges.

\section{HYPOTHALAMIC MECHANISMS IN THE THERMOREGULATORY CONTROL OF BAT THERMOGENESIS}

Within the neural circuits regulating body temperature, the hypothalamus, including the POA, occupies a pivotal position between the cutaneous sensation of ambient temperature and the motor pathways controlling the engagement of thermal effectors (Figure 1). Befitting its function as a central integrator of the many dimensions of homeostatic space, the hypothalamus is composed of several interconnected populations of neurons, receives a variety of signals relating to behavioral and emotional state, as well as the condition of the body and the interstitial fluid, and has outputs influencing emotional, behavioral, somatic, and autonomic responses. Control of body temperature is but one of a myriad of interrelated homeostatic functions embedded in the hypothalamic matrix. Despite the anatomical and neurochemical complexity of this brain region, and the many factors that can influence body temperature regulation, considerable progress has been made in understanding the functional organization of the hypothalamic network that controls BAT thermogenesis.

\section{MnPO neurons receive cutaneous thermal signals driving BAT thermoregulatory responses}

Within the POA, feedforward, cutaneous cool signaling driving BAT thermogenesis is mediated by glutamatergic inputs from LPBel neurons to neurons in MnPO (Figure 1). Stimulation of BAT thermogenesis by activation of LPBel neurons or by skin cooling is blocked by inhibiting neuronal activity in the MnPO (Figure 2) or by antagonizing glutamate receptors in the $\mathrm{MnPO}$ (Nakamura and Morrison, 2008a,b), and glutamatergic stimulation of MnPO neurons evokes increases in BAT SNA and BAT thermogenesis that are similar to cold-defensive BAT responses (Nakamura and Morrison, 2008a). That the POA subregion receiving thermosensory cold signals is confined to the MnPO is supported by the findings that the projections from LPBel neurons activated by skin cooling terminate mainly in a median part of the POA (Nakamura and Morrison, 2008b) and that glutamatergic stimulation or disinhibition of the MnPO with nanoinjections of NMDA or bicuculline, respectively, evokes physiological responses mimicking cold-defensive responses, while the same stimulation of the MPO or LPO does not (Nakamura and Morrison, 2008a). Thus, activation of MnPO neurons is an essential step in the central mechanism for eliciting cold-defensive BAT thermogenesis to environmental cold challenges (Figure 1). MnPO neurons receiving cutaneous thermal signals from LPB neurons also presumably receive other synaptic inputs that could influence the cutaneous thermal afferent regulation of BAT thermogenesis, although the sources of such inputs to these MnPO neurons are unknown. The strong activation of BAT thermogenesis by local nanoinjections of bicuculline into MnPO (Nakamura and Morrison, 2008a) suggests that one such input, at least in anesthetized rats, provides a tonic inhibition of skin cooling-responsive neurons in MnPO.

Stimulation of BAT thermogenesis in response to skin cooling is postulated to occur via a disinhibitory mechanism in which $\mathrm{MnPO}$ neurons receiving cutaneous cool signals from LPBel neurons provide a GABA input to the warm-sensitive, inhibitory projection neurons in the MPO (Figure 1) to reduce their tonic activity, resulting in disinhibition of neurons in caudal brain regions whose excitation stimulates BAT thermogenesis for cold defense. Consistent with this hypothesis, increases in BAT thermogenesis evoked by skin cooling (Figure 2) or by stimulation of MnPO neurons are reversed completely by antagonizing $\mathrm{GABA}_{\mathrm{A}}$ receptors in the MPO 

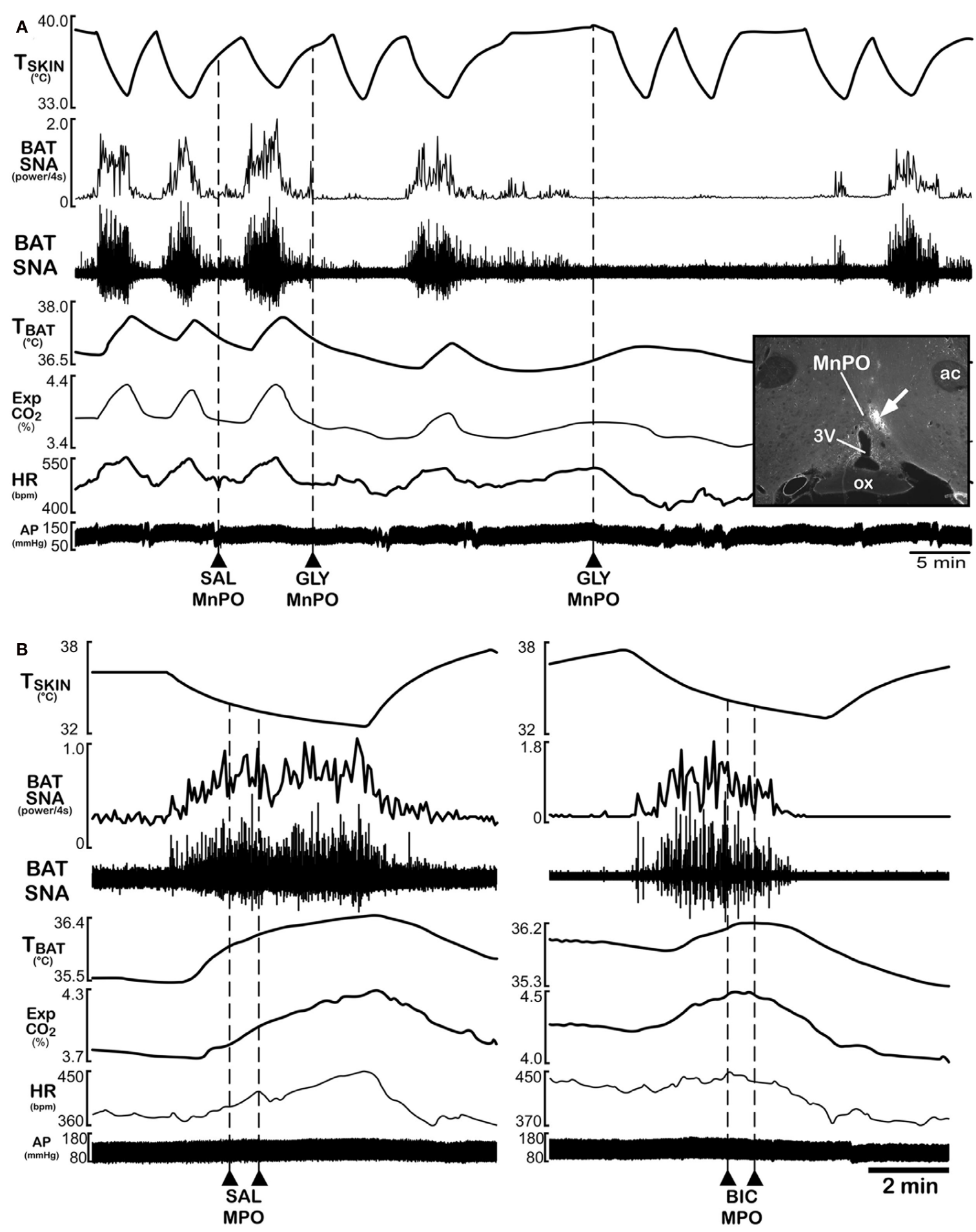

FIGURE 2 | Inhibition of neurons in the median preoptic nucleus (MnPO) or blockade of $\mathrm{GABA}_{\mathrm{A}}$ receptors in the medial preoptic nucleus (MPO) prevents skin cooling-evoked BAT thermogenesis. (A) Before and after injection of saline (SAL) vehicle into the $\mathrm{MnPO}$ [inset: typical injection site (arrow) in the $\mathrm{MnPO} ; 3 \mathrm{v}$, third ventricle; ox, optic chiasm; ac, anterior commissure], episodes of skin cooling evoke increases in BAT sympathetic nerve activity (SNA), BAT temperature (TBAT), expired $\mathrm{CO}_{2}\left(\operatorname{Exp} \mathrm{CO}_{2}\right)$, and heart rate $(\mathrm{HR})$, with no change in arterial pressure (AP). Following nanoinjection of the inhibitory transmitter, glycine (GLY), into the MnPO, skin cooling no longer increases these thermoregulatory parameters. Modified with permission from Nakamura and Morrison (2008a). (B) The skin cooling-evoked increases in thermoregulatory parameters, including BAT SNA and TBAT, are unaffected by nanoinjection of saline vehicle into the MPO, but these increases are reversed by blockade of $\mathrm{GABA}_{\mathrm{A}}$ receptors in MPO with nanoinjection of bicuculline (BIC). Modified with permission from Nakamura and Morrison (2007). 
(Nakamura and Morrison, 2008a). The existence of GABAergic interneurons in the MnPO that innervate the MPO projection neurons is supported by the anatomical observations (a) that some MnPO neurons innervate the MPO (Uschakov et al., 2007), (b) that the MnPO contains many GABAergic neurons (Nakamura et al., 2002), (c) that many neurons in the MnPO, rather than the MPO or LPO, are activated (express Fos protein) in response to reduced environmental temperature (Bratincsak and Palkovits, 2004), and (d) extracellular GABA in the POA is elevated during cold exposure and reduced during heat exposure (Ishiwata et al., 2005).

\section{Warm-sensitive neurons in POA integrate cutaneous and core thermal signals to provide inhibitory regulation of BAT thermogenesis}

The conceptual foundation of our current understanding of the role of the hypothalamus in normal body temperature regulation and in the elevated body temperature during fever is the existence of a class of hypothalamic neurons which have intrinsic temperature sensitivity: in the absence of synaptic inputs, their discharge frequency increases as the temperature of their local environment increases. The neurophysiological mechanism underlying the thermosensitivity of warm-sensitive neurons in the POA is thought to reside in a warming-dependent facilitation of the rate of rise of a depolarizing prepotential, due to an heat-induced increase in the inactivation rate of an A-type potassium current, which shortens the intervals between action potentials and thereby increases their firing rates (Boulant, 2006a). Warm-sensitivity could also arise from a heat-induced membrane depolarization that allows warmsensitive neurons to reach their discharge threshold potential and then determines their discharge frequency (Kobayashi et al., 2006), although the channel mediating such a depolarization has not been identified. Although neurons whose spontaneous discharge frequency is altered by changing the temperature of their local environment exist throughout the CNS, those in the POA and anterior hypothalamus have been most intensely studied because thermoregulatory responses, perhaps with the exception of certain thermoregulatory behaviors (Almeida et al., 2006), are dependent on the integrity of POA neurons. The preeminent importance of central warm-sensitive neurons for the maintenance of normal body temperature can also be appreciated from the relative position of mammalian resting body temperatures well above the freezing point of water, but only a few degrees below the temperature at which proteins begin irreversible denaturation (Romanovsky, 2007).

Initial, in vivo recordings in the POA identified neurons with spontaneous discharge at thermoneutral temperatures that increased their discharge during local hypothalamic warming (i.e., putative warm-sensitive neurons; Nakayama et al., 1961, 1963). The POA contains warm-sensitive neurons whose tonic discharge is also reduced by skin cooling and whose thermosensitivity to preoptic temperature is increased when the skin is cooled (Boulant and Hardy, 1974). In subsequent recordings in the POA in hypothalamic slices, the majority of thermosensitive neurons were warm-sensitive (Boulant and Dean, 1986) and the majority of these were GABAergic (Lundius et al., 2010). Further, either skin cooling or direct cooling of the local environment of POA neurons evokes sympathetic thermogenesis in BAT (Imai-Matsumura et al., 1984) and transections immediately caudal to the POA elicit large increases in BAT temperature (Chen et al., 1998). These findings are consistent with a model (Figure 1) in which warm-sensitive POA neurons that are tonically active at thermoneutral temperatures, integrate cutaneous and local thermal information, and send inhibitory projections from the MPO to suppress BAT thermogenesis. As ambient temperature is reduced below the thermoneutral zone, such as to a normal "room" temperature of $\sim 23^{\circ} \mathrm{C}$, the discharge rate of warm-sensitive POA neurons is reduced, thereby disinhibiting BAT sympathoexcitatory neurons in more caudal brain sites such as the dorsomedial hypothalamus $(\mathrm{DMH})$ or the rostral raphe pallidus ( $\mathrm{rRPa}$; see below) whose increased activity then drives BAT thermogenesis (Figure 1). Thus, the firing rates of warm-sensitive projection neurons in the MPO, potentially the principal neurophysiological substrate underlying the thermoregulatory "balance point" (Romanovsky, 2004), are determined by both thermosensory afferent signals from the skin and by the effect of local brain temperature. Other inputs to POA warm-sensitive neurons, such as those postulated from "temperature-insensitive" neurons (Boulant, 2006b), are expected to influence the level of BAT thermogenesis by affecting the basal discharge level of warmsensitive projection neurons in the MPO or their sensitivity to local and cutaneous thermal signals.

\section{The dorsomedial hypothalamus contains BAT sympathoexcitatory neurons}

The observation that transection of the neuraxis immediately caudal to the POA increases BAT SNA and BAT thermogenesis (Chen et al., 1998) suggests that the efferent output of the POA is inhibitory to BAT thermogenesis. However, transections made just caudal to the hypothalamus do not increase basal levels of BAT thermogenesis in normothermic animals (Rothwell et al., 1983) and, in fact, reverse PGE $_{2}$-evoked increases in BAT SNA and BAT thermogenesis (Morrison et al., 2004; Rathner and Morrison, 2006). Thus, although a long inhibitory pathway from POA warm-sensitive neurons to medullary BAT sympathetic premotor neurons may contribute to the regulation of BAT thermogenesis, a source of excitatory drive to BAT thermogenesis must exist between the POA and the rostral midbrain.

Convincing data support a role for neurons in the $\mathrm{DMH} /$ dorsal hypothalamic area (DMH/DA) in the control of BAT thermogenesis (Dimicco and Zaretsky, 2007), potentially as BAT sympathoexcitatory neurons antecedent to medullary BAT sympathetic premotor neurons in $\mathrm{rRPa}$ (Figure 1). Administration of endotoxin or cold exposure increases the expression of Fos in neurons of the DMH/DA (Elmquist et al., 1996; Cano et al., 2003; Sarkar et al., 2007). Disinhibition of DMH/DA neurons increases BAT SNA (Cao et al., 2004; Figure 3A) and thermogenesis (Zaretskaia et al., 2002), suggesting a tonic GABAergic inhibitory input to BAT thermogenesis-promoting neurons in the DMH/DA (Figure 1). This tonic GABAergic input to neurons in the DMH/DA may originate in the POA since POA-derived GABAergic axon swellings make close appositions with DMH neurons, including those that project to the rRPa (Nakamura et al., 2005). In addition, inhibition of neurons in the DMH/DA or blockade of local glutamate receptors in the DMH/DA reverses febrile and cold-evoked excitations 


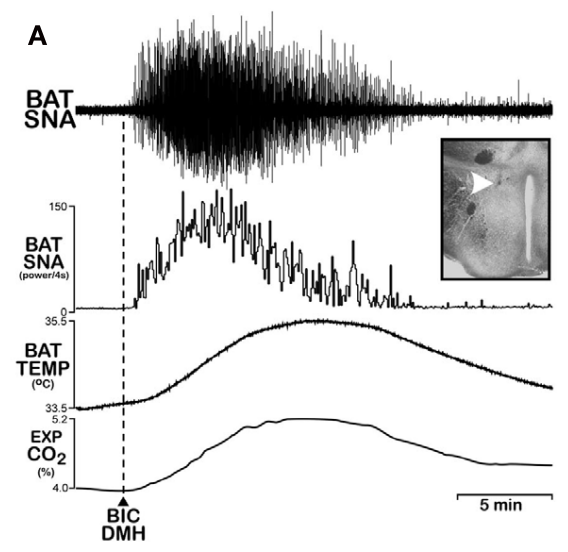

FIGURE 3 | Disinhibition of neurons in the dorsomedial hypothalamus (DMH) increases brown adipose tissue (BAT) thermogenesis and inhibition of neurons in the DMH reverses febrile-evoked BAT sympathetic nerve activity (SNA) and

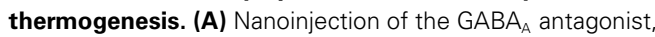
bicuculline $(\mathrm{BIC})$, into the $\mathrm{DMH}$, (white arrowhead in inset histological section through the DMH) increased BAT SNA, BAT temperature (BAT

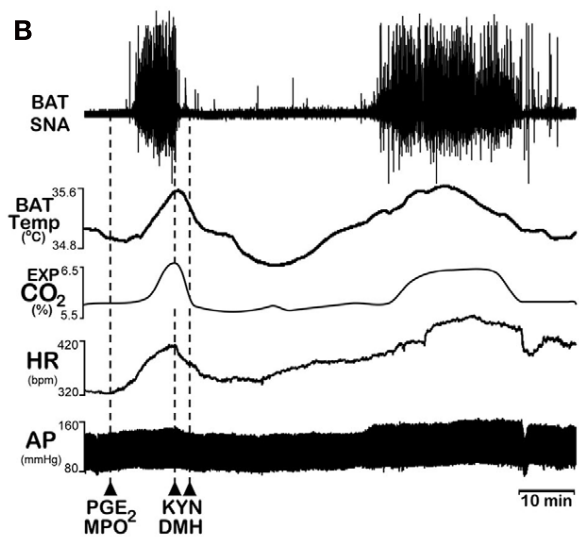

Temp), and expired $\mathrm{CO}_{2}$. Modified with permission from Morrison et al. (2004). (B) Nanoinjection of prostaglandin $E_{2}\left(P G E_{2}\right)$ into the medial preoptic area (MPO) increased BAT SNA, BAT Temp, Exp $\mathrm{CO}_{2}$, heart rate $(H R)$, and arterial pressure (AP). Subsequent bilateral nanoinjection of the glutamate receptor antagonist, kynurenate (KYN), into the DMH completely reversed these $\mathrm{PGE}_{2}$-evoked responses. Modified with permission from Madden and Morrison (2004). of BAT SNA (Figure 3B) and stimulations of BAT thermogenesis (Zaretskaia et al., 2003; Madden and Morrison, 2004; Morrison et al., 2004; Nakamura et al., 2005; Nakamura and Morrison, 2007). Thus, the glutamate-driven activity of neurons in the DMH/DA is required for cold-evoked and febrile activations of BAT thermogenesis, following their disinhibition by a reduction in their GABAergic inhibitory inputs from POA (Figure 1). Although the source of the required excitatory input to DMH/DA neurons accounting for their activity following disinhibitory stimuli has yet to be determined, it could arise from cold-sensitive or thermally insensitive neurons in the POA (Boulant, 2006b) or perhaps from an input from the periaqueductal gray (PAG; de Menezes et al., 2009).

Neurons in the DMH/DA do not project directly to BAT sympathetic preganglionic neurons (SPNs), but their monosynaptic projection to the rostral ventromedial medulla (Hermann et al., 1997; Samuels et al., 2002; Nakamura et al., 2005; Yoshida et al., 2009), including the principal site of BAT sympathetic premotor neurons in the rRPa (see below), has been implicated in mediating the effects of DMH/DA neurons on BAT thermogenesis. Glutamate receptor activation in the $\mathrm{rPP}$ is necessary for the increase in BAT SNA and BAT thermogenesis evoked by disinhibition of neurons in the DMH/DA (Cao and Morrison, 2006). Neurons in the DMH/DA that are retrogradely labeled from tracer injections into the rRPa express Fos in response to BAT thermogenic stimuli such as endotoxin, cold exposure or stress (Sarkar et al., 2007; Yoshida et al., 2009), and some DMH/DA neurons that project to the $\mathrm{rRPa}$ receive close GABAergic appositions from neurons in the MPO (Nakamura et al., 2005).

In addition to the evidence for a direct monosynaptic pathway from the $\mathrm{DMH} / \mathrm{DA}$ to the $\mathrm{RPa}$, both anatomical and physiological evidence suggest a role for neurons in the PAG in determining the level of BAT thermogenesis, potentially by influencing the output from the DMH. Some DMH/DA neurons projecting to the caudal
PAG (cPAG) express Fos in response to cold exposure (Yoshida et al., 2005) and some neurons in the cPAG are multisynaptically connected to BAT (Cano et al., 2003), presumably including those that project directly to the raphe (Hermann et al., 1997). Neurons in the cPAG express Fos in response to cold (Cano et al., 2003), although these may not project to the rRPa (Yoshida et al., 2009). Excitation of neurons in CPAG increases BAT temperature, without a concomitant increase in core temperature (Chen et al., 2002), while similar excitation of neurons in the lateral and dorsolateral PAG (dl/lPAG) of conscious rats increases core temperature, the latter being dependent on activity within the DMH (de Menezes et al., 2009). In contrast, in anesthetized and paralyzed rats, skin cooling-evoked stimulation of BAT thermogenesis was unaffected by muscimol injections into the cPAG (Nakamura and Morrison, 2007). The area of the rostral ventromedial PAG (rvmPAG) contains neurons with an inhibitory effect on BAT thermogenesis that are capable of reversing the BAT thermogenesis evoked by $\mathrm{PGE}_{2}$ injections in to POA or by disinhibition of neurons in DMH/DA (Rathner and Morrison, 2006). Clearly, there is a need for further investigation of the pathways transmitting the sympathetic drive for BAT thermogenesis from the hypothalamus to medullary BAT premotor neurons, and of the roles of various regions of the PAG in regulating BAT thermogenesis.

\section{THE ROSTRAL RAPHE PALLIDUS CONTAINS BAT SYMPATHETIC PREMOTOR NEURONS}

Within the hierarchical organization of the central thermoregulatory network, neurons in the rostral ventromedial medulla, centered in the rRPa and extending into nearby raphe magnus nucleus and over the pyramids to the parapyramidal area (PaPy; Bamshad et al., 1999; Oldfield et al., 2002; Cano et al., 2003; Yoshida et al., 2003), play key roles as BAT sympathetic premotor neurons - providing an essential excitatory drive to BAT SPNs in the thoracolumbar spinal cord, which, in turn, excite sympathetic 
ganglion cells innervating the BAT pads (Figure 1). A comparison of the localization of Fos induced by cold exposure which activates BAT thermogenesis with the locations of retrogradely labeled neurons following virus inoculations of BAT provided function-based evidence that the rRPa (Figure 4A) and the ventromedial parvicellular subdivision of the paraventricular hypothalamic (PVH) nucleus are the two potential premotor populations having principal roles in mediating the descending regulation of the spinal sympathetic circuit controlling BAT thermogenesis during cold defense (Cano et al., 2003). Further functional studies have clearly identified the preeminent role of BAT sympathetic premotor neurons in $\mathrm{rRPa}$ in the cold-defense activation of BAT thermogenesis; however, the role of the Fos-expressing neurons in $\mathrm{PVH}$ remains unknown.

Brown adipose tissue sympathetic premotor neurons in the $\mathrm{rRPa}$ receive a potent glutamatergic excitation, as well as GABAergic inhibitory inputs, with the latter predominating under warm conditions to reduce BAT thermogenesis. Relief of this tonically active, GABAergic inhibition as well as an increase in glutamatemediated excitation, including that from the $\mathrm{DMH}$ (Cao and Morrison, 2006), contributes to the cold-evoked and febrile increases in BAT premotor neuronal discharge that drives BAT SNA and BAT heat production. Nanoinjections into $\mathrm{rRPa}$ of agonists for either NMDA or non-NMDA glutamate receptors evoke brief, but intense activations of BAT SNA (Madden and Morrison, 2003), indicating that neurons in rRPa capable of increasing the sympathetic drive to BAT express NMDA and non-NMDA subtypes of glutamate receptors. That nanoinjections of bicuculline into the rRPa evoke intense activations of BAT SNA (Figure 4B) and BAT energy expenditure (Morrison et al., 1999) that are reduced by glutamate receptor antagonists suggests the existence either of an ongoing or bicuculline-activated excitatory input to rRPa BAT sympathetic premotor neurons.

Conversely, inhibition of neuronal activity or blockade of glutamate receptors in the rRPa reverses the increases in BAT SNA and BAT thermogenesis elicited by a variety of thermogenic stimuli, including skin cooling (Figure 4C) and fever (Nakamura et al., 2002; Madden and Morrison, 2003; Morrison, 2003; Nakamura and Morrison, 2007; Ootsuka et al., 2008). Inhibition of rostral ventromedial medullary neurons produces dramatic falls in body temperature in conscious rats (Zaretsky et al., 2003), consistent with an active contribution of BAT sympathetic premotor neurons in the rRPa and BAT thermogenesis to the maintenance of core temperature in a room temperature environment. Other thermogenic stimuli whose activation of BAT thermogenesis is reversed or prevented by inhibition of neural activity in the rRPa include disinhibition of neurons in the DMH (Cao et al., 2004) or in the lateral hypothalamus (Cerri and Morrison, 2005); activation of central mu-opioid receptors (Cao and Morrison, 2005), central melanocortin receptors (Fan et al., 2007) or preoptic CRF receptors (Cerri and Morrison, 2006), and systemic administration of the adipose tissue hormone, leptin (Morrison, 2004). Thus, the rRPa and PaPy regions of the ventromedial medulla contain the principal populations of BAT sympathetic premotor neurons that provide the final common medullospinal pathway (Figure 1) for the BAT sympathoexcitatory drive to the spinal network controlling BAT SNA and that are both necessary and sufficient for the

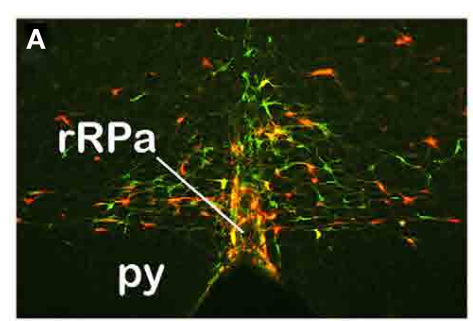

B
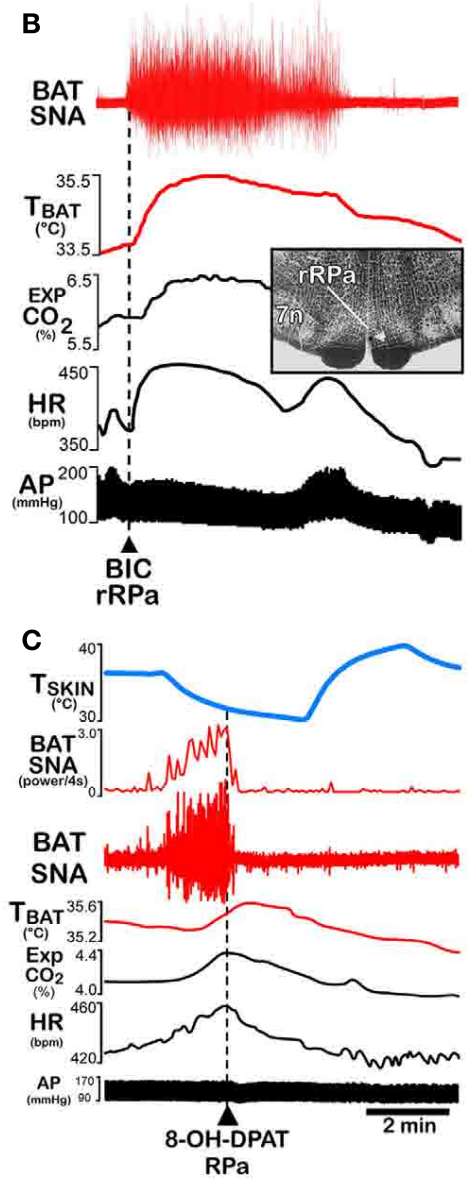

FIGURE 4 | Effects of disinhibition and inhibition of rostral raphe pallidus ( $\mathrm{rRPa}$ ) neurons on brown adipose tissue (BAT) thermogenesis. (A) Coronal histological section through the rostral medulla at the level of the facial nucleus and the rRPa, containing immunohistochemically labeled neurons that were trans-synaptically infected following inoculations of BAT with pseudorabies virus (red), that contain the serotonin synthesizing enzyme, tryptophan hydroxylase (green), or that contain both markers (yellow). Py, pyramidal tract. Modified with permission from Cano et al. (2003). (B) Disinhibition of neurons in the rRPa [arrowhead in inset histological section through $\mathrm{rRPa}$ at the level of the facial nucleus (7n)] with nanoinjections of bicuculline $(B I C)$ elicits dramatic increases in BAT sympathetic nerve activity (SNA), BAT temperature (TBAT), expired $\mathrm{CO}_{2}$ $\left(\right.$ Exp $\left.\mathrm{CO}_{2}\right)$, and heart rate $(\mathrm{HR})$, with little change ion arterial pressure (AP). Modified with permission from Madden and Morrison (2003). (C) Inhibition of local neurons in the rRPa with a nanoinjection of the inhibitory serotonin $1 \mathrm{~A}$ receptor agonist, 8-OH-DPAT, produces a rapid and complete reversal of the skin cooling-evoked increases in BAT SNA and an immediate waning of the accompanying metabolic and cardiac responses, despite the sustained reduction in skin temperature (TSKIN). Modified with permission from Nakamura and Morrison (2007). 
BAT thermogenic responses to thermoregulatory (Figure 1) and febrile stimuli and to a variety of neurochemical mediators that influence body temperature.

That vesicular glutamate transporter 3 (VGLUT3)-expressing and serotonin-containing neurons in the rostral ventromedial medulla are functionally related to the activation of cold-defensive, BAT thermogenesis is indicated by the findings that a significant percentage of VGLUT3-containing neurons in the rRPa express Fos in response to cold exposure or intracerebroventricular (ICV) PGE $_{2}$ (Nakamura et al., 2004a) and that physiologically identified serotonergic neurons in the $\mathrm{rPa}$ increase their firing rate in response to $\mathrm{PGE}_{2}$ administration or cold exposure (Martin-Cora et al., 2000).

Rats maintained with a brainstem transection just rostral to the superior colliculus (Nautiyal et al., 2008) or with bilateral cuts just caudal to the POA (Blatteis and Banet, 1986) can mount relatively normal cold-defense responses, leading to the conclusion that the POA is not essential for the integration of autonomic thermoregulatory responses in the rat and that circuits caudal to the transection are sufficient to convey cutaneous thermal information to the premotor neurons in the rRPa necessary to evoke cold-defense responses. Why the pathways proposed by these investigators to explain these effects in transected rats are ineffective in intact rats following neuronal inhibition of hypothalamic sites in intact animals (Zaretskaia et al., 2003; Madden and Morrison, 2004; Nakamura and Morrison, 2007, 2008a) remains unexplained. These results may point to an effect of anesthesia or to a response to the transection injury, since they could not be repeated acutely following nearly identical transections rostral to the colliculi in anesthetized rats (Osaka, 2004). Thermally sensitive neurons have been recognized in several sites caudal to the POA and these neurons, rather than cutaneous thermal receptors, may be engaged in eliciting cold-defense responses in rats with transections caudal to the POA. Overall, while these occasional data derived from transected preparations are curious, their relevance to normal thermoregulatory mechanisms in intact animals remains unknown.

\section{SPINAL SYMPATHETIC MECHANISMS INFLUENCING BAT THERMOGENESIS}

The discharge of BAT SPNs that determines the level of BAT SNA and BAT thermogenesis, as well as the rhythmic bursting characteristic of BAT SNA, is governed by their supraspinal and segmental inputs as well as those to the network of spinal interneurons that influence BAT SPN excitability. A significant fraction of the BAT sympathetic premotor neurons in $\mathrm{rRPa}$, identified following viral retrograde tracing, are glutamatergic and/or serotonergic neurons. Spinally projecting neurons in the rRPa region can contain phenotypic markers for (a) the VGLUT3, potentially indicative of glutamatergic neurons (Nakamura et al., 2004a; Stornetta et al., 2005); (b) serotonin (5-HT) or tryptophan hydroxylase, a synthetic enzyme for 5-HT (Cano et al., 2003; Nakamura et al., 2004a; Stornetta et al., 2005), and (c) glutamic acid decarboxylase-67 (GAD-67), a marker for GABAergic neurons (Stornetta et al., 2005). Consistent with these findings, 5-HT-containing (Bacon and Smith, 1988; Vera et al., 1990) and VGLUT3-containing terminals synapse on SPNs (Stornetta et al., 2005) or make close appositions with SPN dendrites (Nakamura et al., 2004a,b). In addition, IML-projecting neurons located in the rRPa and the $\mathrm{PaPy}$ can contain thyrotropin-releasing hormone (TRH) and substance P (Sasek et al., 1990).

Glutamate and 5-HT play critical roles in the descending excitation of BAT SPNs by their antecedent premotor neurons in the $\mathrm{rRPa}$. The majority of VGLUT3-containing neurons in the $\mathrm{rRPa}$ express Fos in response to cold exposure or ICV PGE 2 (Nakamura et al., 2004a), nanoinjection of glutamate or NMDA into the upper thoracic IML activates BAT SNA and BAT thermogenesis (Nakamura et al., 2004a; Madden and Morrison, 2006) and blockade of glutamate receptors in the upper thoracic IML suppresses the increase in BAT thermogenesis evoked by bicuculline injection into rRPa (Nakamura et al., 2004a). Putative serotonergic neurons in the rRPa increase their firing rate in response to cold (MartinCora et al., 2000; Nason and Mason, 2006) or $\mathrm{PGE}_{2}$ administration (Nason and Mason, 2006) and blockade of spinal serotonin receptors reverses the cold-evoked activation of BAT SNA (Madden and Morrison, 2010). Serotonin in the IML can activate BAT SNA and BAT thermogenesis and potentiates the BAT SNA response to NMDA injections into the IML (Madden and Morrison, 2006), such that prior application of serotonin into the IML allows a subsequent subthreshold dose of NMDA to evoke a marked increase in BAT SNA (Madden and Morrison, 2006). The significant role of serotonin-containing neurons in normal cold-defense responses is also supported by the finding that mice that lack almost all central serotonergic neurons show blunted BAT thermogenesis during cold exposure (Hodges et al., 2008). The mechanisms of the interaction between glutamatergic and serotonergic neurotransmission in the IML remain to be elucidated.

Viral inoculations of interscapular BAT (Cano et al., 2003) consistently label a population of spinal interneurons in the vicinity of the IML. Spinal GABAergic interneurons would appear to be among this population since they influence the discharge of SPNs (Deuchars et al., 2005). That such interneurons could receive inputs from the BAT premotor area in the rostral ventromedial medulla is suggested by the demonstration that VGLUT3and GAD-67-containing terminals synapse on GABAergic neurons in the IML (Stornetta et al., 2005), providing a potential anatomical substrate for a pathway that increases the activity of SPNs through disinhibition. 5-HT-containing terminals form close appositions with GABAergic interneurons in the central autonomic area (Conte et al., 2007) and serotonergic inputs activating $5-\mathrm{HT}_{1 \mathrm{~A}}$ receptors on GABAergic neurons in the IML have been postulated to explain the potentiation of excitatory inputs to BAT SPNs by exogenously applied 5-HT (Madden and Morrison, 2006, 2008a).

Spinal catecholamine release may also modulate the activity of BAT SPNs, considering the excitatory and inhibitory effects of catecholamines on functionally unidentified SPNs (Coote et al., 1981; Miyazaki et al., 1989) and the observation of a dense dopamine beta hydroxylase innervation of SPNs that are synaptically connected to BAT (Cano et al., 2003). Substance P terminals also innervate SPN's (Vera et al., 1990), substance P excites the majority of SPNs (Cammack and Logan, 1996), and intrathecal substance P affects thermoregulation (Dib, 1987), although the latter may be due to an effect on thermal afferent processing in the dorsal horn. 


\section{ACTIVATION OF BAT THERMOGENESIS IN FEVER}

Fever is a defended elevation in body temperature that plays a significant role in the acute phase reaction stimulated by endogenous pyrogens released during infection or inflammation. $\mathrm{PGE}_{2}$, which is synthesized in the brain vasculature and in peripheral tissues in response to immune signals (Elmquist et al., 1997; Matsumura et al., 1998; Yamagata et al., 2001), is a powerful endogenous pyrogenic mediator that binds to $\mathrm{EP} 3$ receptors in the $\mathrm{POA}$, particularly the MPO and MnPO (Scammell et al., 1996; Nakamura et al., 2000, 2002; Lazarus et al., 2007), to activate BAT thermogenesis in concert with other thermoregulatory effectors to produce a sustained increase in core body temperature. Intravenous $\mathrm{PGE}_{2}$ is also effective in eliciting the BAT thermogenic component of the febrile response (Ootsuka et al., 2008).

Although we have only a rudimentary understanding of the microcircuitry of the POA thermoregulatory network, we have proposed (Nakamura et al., 2004a, 2005) a model, incorporated in Figure 1, for the essential POA mechanisms through which application of $\mathrm{PGE}_{2}$ into the POA elicits the BAT thermogenic component of the febrile response. As described above for cold-defense responses, under normal conditions, EP3 receptor-expressing POA neurons, potentially including the population of warm-sensitive POA neurons that controls BAT thermogenesis, maintain a tonic GABAergic inhibition of sympathoexcitatory, BAT thermogenesispromoting neurons in the $\mathrm{DMH}$, and potentially in the rRPa. During infection, $\mathrm{PGE}_{2}$, produced locally and/or systemically, binds to these EP3 receptors, reducing the activity of BAT-controlling, warm-sensitive neurons in POA, which, in turn, leads to disinhibition of BAT thermogenesis-promoting neurons in DMH/DA and subsequently in $\mathrm{rRPa}$, to drive BAT sympathetic outflow and BAT heat production contributing to an elevated core body temperature. Although the resulting increase in the local temperature of the POA would normally elicit more rapidly rising prepotentials in POA warm-sensitive neurons to inhibit BAT activation, this is offset by the membrane hyperpolarization elicited by EP3 receptor occupancy, thereby allowing a sustained activation of BAT thermogenesis and a maintained fever.

Several experimental findings are consistent with such a model. Binding of $\mathrm{PGE}_{2}$ to $\mathrm{EP} 3$ receptors can inhibit neuronal activity by coupling to inhibitory GTP-binding proteins (Narumiya et al., 1999) and the tonic activity of most warm-sensitive neurons in the POA is inhibited by the E-series of PGs (Schoener and Wang, 1976; Ranels and Griffin, 2003). A population of EP3 receptor-expressing POA neurons multisynaptically innervates BAT (Yoshida et al., 2003) and a subpopulation of EP3 receptor-expressing neurons in the POA projects directly to the DMH (Nakamura et al., 2002, 2005). Interestingly, this subpopulation is separate from the subpopulation of EP3 receptor-expressing POA neurons projecting to the $\mathrm{rRPa}$, although a population of POA neurons that do not express EP3 receptors does send bifurcating axonal projections to both DMH and the rRPa (Nakamura et al., 2009). The majority of EP3 receptor-expressing POA neurons are GABAergic (Nakamura et al., 2002), as are warm-sensitive neurons in POA (Lundius et al., 2010). Antagonizing $\mathrm{GABA}_{\mathrm{A}}$ receptors in the $\mathrm{DMH}$ evokes a fever-like stimulation of BAT thermogenesis (Morrison, 1999; Morrison et al., 1999; Zaretskaia et al., 2002; Cao et al., 2004) that is also reversed by blockade of glutamate receptors in the $\mathrm{rRPa}$ (Cao and Morrison, 2006). Inhibition of POA neurons with a muscimol nanoinjection elicits hyperthermic, cardiovascular, and neuroendocrine responses similar to those evoked by a $\mathrm{PGE}_{2}$ nanoinjection into the same site (Zaretsky et al., 2006). In addition, ICV PGE 2 application reduces cAMP level in the POA and ICV administration of an inhibitor of phosphodiesterase, a degradation enzyme for cAMP, blunts fever evoked by intra-POA $\mathrm{PGE}_{2}$ application (Steiner et al., 2002). A marked increase in core temperature and a tachycardia can be elicited by injection of $\mathrm{PGE}_{2}$ into the paraventricular nucleus of the hypothalamus $(\mathrm{PVH})$ or into the pontine parabrachial nucleus (PBN; Skibicka et al., 2011), although whether neurons in these two sites play a role in fever generation remains to be determined. In this regard, the demonstration that elimination of EP3-R selectively in the POA is sufficient to prevent LPS fever (Lazarus et al., 2007) indicates that EP3-R in PVH or in $\mathrm{PBN}$ is not sufficient to support a febrile response or possibly that $\mathrm{PGE}_{2}$ is not increased in these regions during a febrile stimulus such as LPS.

\section{OREXIN IN rRPa INCREASES BAT THERIMOGENESIS}

Orexins (hypocretins; de Lecea et al., 1998; Sakurai et al., 1998) are synthesized exclusively in widely projecting (Peyron et al., 1998) neurons in the perifornical area of the lateral hypothalamus (PeFLH). Orexin neurons influence a variety of functions, including the regulation of food intake (Sakurai et al., 1998). ICV administration of orexin also increases activity and body temperature (Monda et al., 2001). Loss of orexin neurons leads to the disordered sleep patterns of narcolepsy, which is often accompanied by defective energy and metabolic homeostasis, including a high risk for obesity (Kok et al., 2003; Hara et al., 2005) and the potential for altered thermoregulation (Plazzi et al., 2011). Interestingly, systemic orexin, perhaps secreted from the placenta, is required for BAT differentiation and its absence during early development leads to obesity arising from inadequate BAT energy expenditure (Sellayah et al., 2011).

A role for orexin neurons in the PeF-LH in the regulation of BAT thermogenesis has recently been described (Tupone et al., 2011). An anatomical substrate for the influence of orexinergic neurons on BAT thermogenesis is provided by the demonstration that the PeF-LH contains orexinergic neurons that are synaptically coupled to BAT, as shown with viral, trans-synaptic retrograde tracing (Oldfield et al., 2002; Berthoud et al., 2005; Tupone et al., 2011), and that project to the $\mathrm{rRPa}$, as shown with retrograde transport of $\mathrm{CTb}$ following injections into the $\mathrm{rPa}$ region containing BAT sympathetic premotor neurons (Tupone et al., 2011). In anesthetized rats, both injections of orexin into rRPa (Figure 5C) and glutamatergic activation of orexinergic neurons by nanoinjections of NMDA into the PeF-LH (Figure 5C) produced long lasting activations of BAT SNA and BAT thermogenesis, accompanied by marked increases in energy expenditure, indicated by sustained increases in expired $\mathrm{CO}_{2}$ that paralleled the increases in BAT heat production (Figure 5A). Curiously, the strong stimulation of BAT SNA and BAT thermogenesis elicited by injection of orexin into the rRPa or by activation of neurons in the PeF-LH required an ongoing, basal level of BAT SNA, generated in this case by maintaining the rats at a slightly cooled core body temperature. When the rats were warmed to eliminate any basal discharge on the sympathetic 

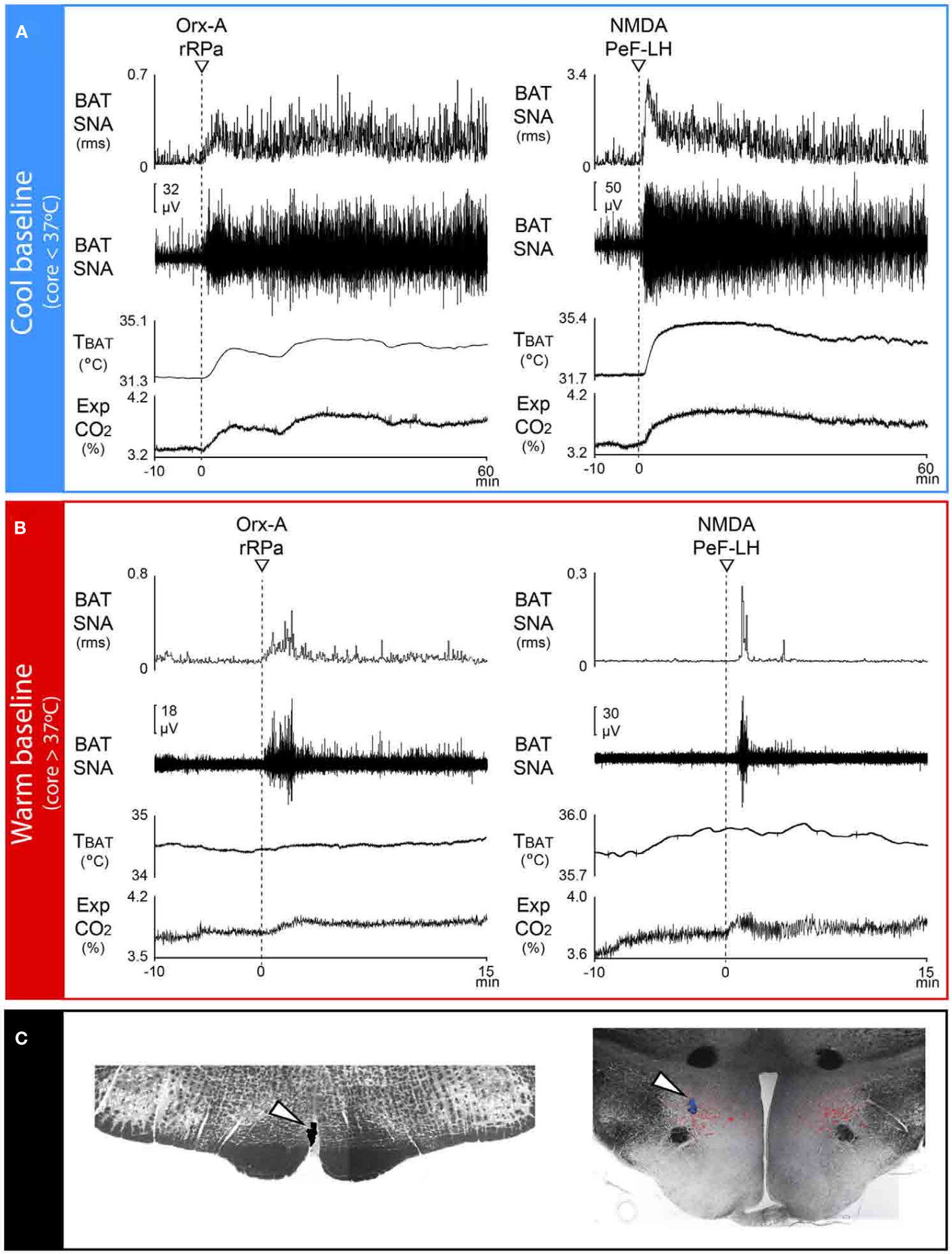

FIGURE 5 | Orexin in the rostral raphe pallidus ( $\mathrm{rRPa}$ ) or activation of neurons in the perifornical lateral hypothalamus (PeF-LH) produces a prolonged increase in BAT sympathetic nerve activity (SNA) and BAT thermogenesis in cool, but not warm rats. (A) Under cool conditions (core temperature $<37^{\circ} \mathrm{C}$ ) in which a low level of basal BAT SNA is present, nanoinjections of orexin-A (Orx-A, left panel, dashed line) in the rRPa or of N-methyl-D-aspartate (NMDA, right panel, dashed line) into the PeF-LH elicited prolonged increases in BAT SNA, BAT temperature (TBAT), and expired $\mathrm{CO}_{2}\left(\operatorname{Exp} \mathrm{CO}_{2}\right)$. (B) Under warm conditions (core temperature $>37^{\circ} \mathrm{C}$ ) in which no basal BAT SNA was present, nanoinjections of Orx-A (left panel, dashed line) in rRPa or of NMDA (right panel, dashed line) into the PeF-LH failed to evoke significant changes in BAT SNA, TBAT or Exp $\mathrm{CO}_{2}$. (C) Representative histological sections illustrating nanoinjection sites in the rRPa (left panel, white arrowhead) and in the PeF-LH (right panel, white arrowhead). Note that the NMDA injection sites in the PeF-LH were located in the midst of many neurons

immunohistochemically labeled for Orexin-A (red). Modified with permission from Tupone et al. (2011). 
nerves to BAT, neither injection of orexin into rRPa nor activation of PeF-LH neurons elicited increases in BAT SNA (Tupone et al., 2011; Figure 5B).

These anatomical data demonstrate not only an orexinergic projection from neurons in the PeF-LH to the site of BAT sympathetic premotor neurons in the $\mathrm{rRPa}$, but also a synaptic connection between orexin-containing neurons in PeF-LH and BAT sympathetic premotor neurons. Physiologically, the requirement for an ongoing level of BAT SNA, and thus an activation of BAT sympathetic premotor neurons in $\mathrm{rRPa}$, in order for orexin in $\mathrm{rRPa}$ to evoke large and sustained increases in BAT SNA and BAT thermogenesis is consistent with a role for orexin in $\mathrm{rRPa}$ to change the gain of the response of BAT sympathetic premotor neurons to their activating, presumably glutamatergic excitatory inputs.

The physiological conditions which activate the orexin neurons in PeF-LH that project to rRPa to modulate the gain of the synaptic drive to BAT sympathetic premotor neurons and facilitate BAT thermogenic responses remains to be determined. Also unknown are the other potential projection targets of the orexin neurons that influence BAT thermogenesis. However, a potential role of orexin neurons in feeding could suggest a simultaneous increase in energy consumption in BAT under conditions of a high level of stored calories. Alternatively, the activation of orexin neurons in awake or aroused states could suggest an accompanying facilitation of BAT thermogenesis to increase brain and core temperatures to optimize performance. In this regard, it would be of interest to determine if the level of activity in orexin neurons parallels the ultradian oscillations in the BAT thermogenesis (Ootsuka et al., 2009). Conversely, a reduction in the activity of the orexinergic input to rRPa may contribute to the reductions in BAT thermogenesis, energy consumption, and body temperature under conditions of sleep, hibernation or starvation.

\section{A ROLE FOR THE VENTROMEDIAL HYPOTHALAMUS IN BAT THERMOGENESIS REMAINS UNCLEAR}

The seminal study of Hetherington and Ranson (1940) initiated the interest in the ventromedial hypothalamus ( $\mathrm{VMH})$ in energy homeostasis and several succeeding studies have suggested that the VMH affects energy expenditure via sympathetic activation of BAT thermogenesis. Electrical stimulation of the VMH increases BAT thermogenesis (Perkins et al., 1981; Minokoshi et al., 1986) and microinjection of glutamate (Yoshimatsu et al., 1993) or triiodothyronine (Lopez et al., 2010) into VMH increases BAT SNA. Conversely, lesions of the VMH attenuate BAT SNA (Niijima et al., 1984; Sakaguchi et al., 1988). However, the methodologies used in these studies, including electrical stimulation, electrolytic lesions, and large injection volumes (i.e., 100-200 $\mathrm{nl}$ for microinjection studies without appropriate anatomical control experiments) significantly limit the conclusions that can be drawn from the resulting data. Furthermore, the close proximity of the VMH to other regions involved in the sympathetic regulation of BAT thermogenesis, including the $\mathrm{DMH}$, the arcuate nucleus and the lateral hypothalamus, and the frequent absence of histological data in these previous studies precludes any conclusions on the role of neurons in the VMH in the control of BAT thermogenesis and BAT energy expenditure. An additional confound is that trans-synaptic retrograde tracing studies have consistently failed to identify any significant population of neurons in the $\mathrm{VMH}$ following injection of pseudorabies virus in BAT, even at long post-inoculation times (Bamshad et al., 1999; Oldfield et al., 2002; Cano et al., 2003; Yoshida et al., 2003). Nonetheless, a recent study found impaired diet-induced thermogenesis and lower levels of UCP1 in BAT in mice lacking PI3K specifically in the SF-1 containing neurons of the $\mathrm{VMH}$ (Klockener et al., 2011), suggesting a role for $\mathrm{VMH}$ neurons in the regulation of BAT. Whether this alteration in BAT UCP1 expression is mediated by a direct effect of altered VMH neuronal discharge on the sympathetic input to BAT, and if so, how this observation might be reconciled with the lack of viral tracer labeling of VMH neurons following inoculation of BAT, remain interesting areas for future study.

\section{INHIBITORY REGULATION OF BAT THERMOGENESIS HYPOXIA INHIBITS BAT THERMOGENESIS}

The brainstem contains the pathways mediating the inhibition of BAT thermogenesis in response to arterial hypoxia, a reflex to restrict oxygen consumption in the face of reduced oxygen availability or compromised oxygen diffusion and transport in the blood. Systemic hypoxia or bolus systemic injections of sodium cyanide produce a prompt and complete reversal of the BAT SNA activations evoked by hypothermia and by $\mathrm{PGE}_{2}$ in the POA and this response to hypoxia is eliminated by section of the carotid sinus nerves or by inhibition of second-order arterial chemoreceptor sensory neurons in the commissural region of the nucleus of the tractus solitarius (NTS; Madden and Morrison, 2005). Interestingly, hypoxia also eliminates the BAT SNA activation resulting from bicuculline nanoinjection into the $\mathrm{rRPa}$, suggesting that activation of a GABAergic input to BAT sympathetic premotor neurons in $\mathrm{rRPa}$ is unlikely to mediate the hypoxic inhibition of BAT thermogenesis. Indirect evidence points to a possible role for a spinal inhibitory mechanism. Similar to arterial hypoxia, disinhibition of neurons in the rostral ventrolateral medulla (RVLM) reduces the BAT SNA activation following bicuculline into the rRPa (Morrison et al., 1999) and both anatomical (Stornetta et al., 2004) and electrophysiological (Deuchars et al., 1997) studies support the existence of a bulbospinal inhibitory pathway to SPNs from the RVLM. The pathway for the hypoxic inhibition of BAT metabolism between the NTS and the BAT SPNs remains to be investigated.

\section{HYPOGLYCEMIA AND GLUCOPRIVATION INHIBIT BAT THERMOGENESIS}

Similar to the hypoxia-evoked inhibition of thermogenesis, hypoglycemia and glucoprivation cause hypothermia (Freinkel et al., 1972; Mager et al., 1976), at least in part by inhibiting sympathetically mediated metabolism in BAT (Egawa et al., 1989a; Madden, 2012). This neurally regulated decrease in metabolism reduces cellular oxidative demands during conditions of reduced availability of metabolic fuel. The importance of this adaptive response, which spares scarce glucose resources for use by critical tissues such as the brain, at the expense of thermoregulation, is demonstrated by the observation that prevention of hypothermia during severe hypoglycemia results in increased mortality rates (Buchanan et al., 1991).

Glucoprivation selectively within the lateral hypothalamus reduces BAT SNA by 25\% (Egawa et al., 1989b), whereas systemic 
glucoprivation can completely inhibit BAT SNA (Egawa et al., 1989a; Madden, 2012). More recently we have demonstrated not only that the glucoprivic agent, 2-deoxy-D-glucose (2-DG), reversed the cooling-evoked activation of BAT SNA, but that selective glucoprivation with local nanoinjection of 5-thio-D-glucose (5-TG) within the ventrolateral medulla (VLM) also completely reversed the cooling-evoked activation of BAT SNA (Madden, 2012). Interestingly, intravenous administration of 2-DG did not attenuate the activation of BAT SNA following pontomedullary transection, suggesting that the hypoglycemia-evoked inhibition of BAT SNA is not mediated solely by circuits within the medulla (Madden, 2012). The NPY/catecholaminergic projection from the VLM to the PVH may play an important role in the glucoprivic inhibition of BAT SNA, consistent with the role of VLM neurons in the glucoprivic inhibition of BAT SNA, the ability of neuronal activation in the PVH to inhibit BAT SNA (see below) and the established role of the NPY/catecholaminergic input from the VLM to the PVH in other counterregulatory responses to hypoglycemia (Ritter et al., 2011). Identifying the respective contributions of hypothalamic and medullary regions to the reduced BAT thermogenesis during conditions of reduced availability of metabolic fuel, as well as the characterization of the specific neural pathways by which hypoglycemia influences thermoregulatory neural circuits await further research.

\section{NEURONS IN THE PARAVENTRICULAR HYPOTHALAMIC NUCLEUS INHIBIT BAT THERMOGENESIS}

The PVH plays a major role in energy homeostasis, influencing both food intake and energy expenditure. Although the paucisynaptic connection of neurons in the PVH to BAT (Bamshad et al., 1999; Oldfield et al., 2002; Cano et al., 2003; Yoshida et al., 2003 ) strongly supports a role for these neurons in the sympathetic regulation of BAT thermogenesis, their influence on the regulation of BAT thermogenesis has been controversial. Initially, neurons in the PVH were thought to play a role in the excitation of BAT SNA, since neurons in the dorsal PVH with direct projections to the spinal sympathetic preganglionic cell column are activated during fever (Zhang et al., 2000) and lesions of PVH attenuate fever (Horn et al., 1994; Caldeira et al., 1998; Lu et al., 2001). Curiously, coldevoked BAT thermogenesis was unaffected by lesions of the PVH (Lu et al., 2001). In contrast, activation of neurons in the PVH has recently been demonstrated to inhibit BAT SNA and BAT thermogenesis (Madden and Morrison, 2009). Unilateral disinhibition of neurons in PVH with nanoinjections of bicuculline or their glutamatergic activation with NMDA injections completely inhibits increases in BAT SNA and BAT thermogenesis elicited by skin and core cooling (Figure 6A), by injections of $\mathrm{PGE}_{2}$ into the MPO that mimic fever, or by disinhibition of neurons in the DMH/DA (Madden and Morrison, 2009). Although activation of PVH neurons could attenuate the increases in BAT SNA and BAT thermogenesis evoked by injections of NMDA into the $\mathrm{rRPa}$, those resulting from bicuculline injections into $\mathrm{rRPa}$ were unaffected by disinhibition of PVH neurons (Figure 6B), consistent with the PVH-evoked inhibition of BAT SNA being mediated by $\mathrm{GABA}_{A}$ receptors in the $\mathrm{rRPa}$. That neurons in the PVH provide an inhibitory influence on BAT SNA is also supported by the observations that NPY presynaptically inhibits GABA release onto PVH neurons (Cowley et al., 1999) and microinjection of NPY into the PVH decreases BAT SNA (Egawa et al., 1991). These apparent controversies in the relation of PVH neurons to BAT thermogenesis, particularly during fever, might be explained by the presence of subpopulations of PVH neurons mediating contrasting effects or by a role of $\mathrm{PVH}$ neurons during fever that involves the stimulation of other feversupporting effector systems such as the cutaneous vasculature or hormone release, whereas the inhibition of BAT thermogenesis by $\mathrm{PVH}$ neurons contributes to a non-febrile homeostatic function.

Controversy also exists concerning the role of melanocortin receptor activation in the $\mathrm{PVH}$ in energy expenditure and activation of BAT thermogenesis. Selective rescue of melanocortin-4 receptor (MC4R) expression in neurons of the $\mathrm{PVH}$ (and the medial amygdala) in mice lacking expression of MC4R failed to normalize (elevate) their oxygen consumption to wild-type levels (Balthasar et al., 2005). Based on these data it was suggested that PVH MC4Rs do not mediate the energy expenditure effects of melanocortins. In contrast, other groups have demonstrated that microinjection of melanocortin receptor agonists into the $\mathrm{PVH}$ increases core and BAT temperatures (Song et al., 2008; Skibicka and Grill, 2009). These effects of melanocortin receptor activation could be mediated by activation of presynaptic MC4Rs, which have been shown to potentiate GABAergic inputs to PVH neurons (Cowley et al., 1999). Indeed, this explanation would reconcile this controversy, since the rescue of MC4R in the study of Balthasar et al. would only rescue the postsynaptic MC4R in PVH neurons and not those located presynaptically and potentially responsible for the effects of exogenously administered melanocortin receptor agonists. This explanation is also consistent with our data indicating that the activity of neurons in the PVH is inhibitory to BAT SNA. The physiological conditions which would stimulate the BAT sympathoinhibitory output from the PVH are unknown, but may include hypoglycemia and chronic intermittent hypoxia. Another interesting possibility is that neurons in the $\mathrm{PVH}$ provide a tonic inhibition of BAT thermogenesis and release from this inhibition under specific conditions, such as changes in dietary composition, may activate BAT SNA and BAT energy expenditure.

\section{PONTINE RETRORUBRAL FIELD NEURONS MAINTAIN A TONIC INHIBITION OF BAT THERMOGENESIS}

The existence of a tonically active inhibition of BAT thermogenesis from mid-pontine neurons (Figure 1) was indicated by the large increases in BAT and/or core temperatures that followed transections of the neuraxis in the vicinity of the pontomedullary junction, but which were absent if transections were made rostral to the pons, but caudal to the DMH (Rothwell et al., 1983; Amini-Sereshki and Zarrindast, 1984). Inactivation of neurons in the vicinity of the pontine retrorubral field produced a similar stimulation of BAT thermogenesis (Shibata et al., 1999). Neither the exact location of the neurons mediating this inhibition nor the physiological basis for its control has been determined.

\section{INHIBITION OF BAT THERMOGENESIS FROM NEURONS IN THE VENTROLATERAL MEDULLA AND THE NUCLEUS OF THE SOLITARY TRACT}

The VLM and the NTS contain neurons that comprise fundamental cardiovascular and respiratory regulatory circuits, including 
the baroreceptor and arterial chemoreceptor reflex pathways regulating local vasoconstrictor and cardiac sympathetic premotor neurons, as well as the respiratory generating network and its regulation by central chemoreceptors. A role for neurons in these same regions in regulating BAT thermogenesis has been recently described (Cao et al., 2010). Disinhibition of neurons in the VLM with a unilateral nanoinjection of bicuculline elicits a prompt and complete inhibition of the increased BAT SNA and BAT thermogenesis due to skin and core cooling (Figure 7A), to injections of $\mathrm{PGE}_{2}$ into the MPO, to disinhibition of neurons in DMH/DA or

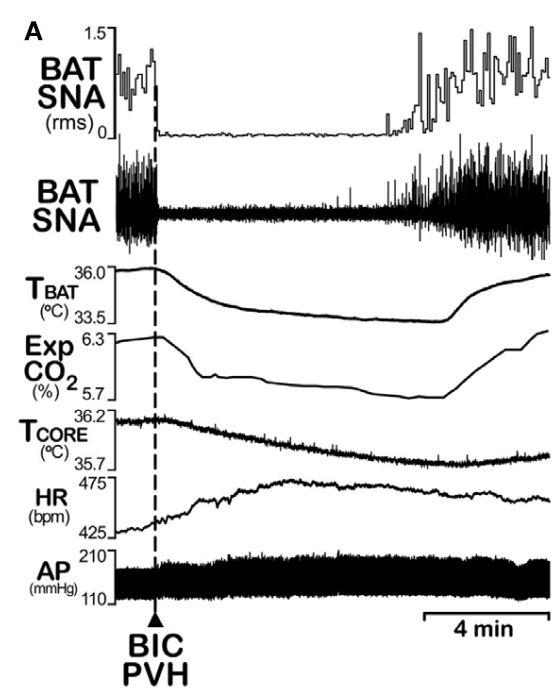

FIGURE 6 | Disinhibition of neurons in the paraventricular hypothalamic (PVH) nucleus inhibits the increases in BAT sympathetic nerve activity (SNA) evoked by cooling, but not those evoked by disinhibition of neurons in the rostral raphe pallidus ( $\mathrm{RPa}$ ). (A) Nanoinjection of bicuculline $(\mathrm{BIC})$ into the $\mathrm{PVH}$ completely reversed the increases in BAT SNA, BAT temperature (TBAT), expired $\mathrm{CO}_{2}\left(\operatorname{Exp~} \mathrm{CO}_{2}\right)$

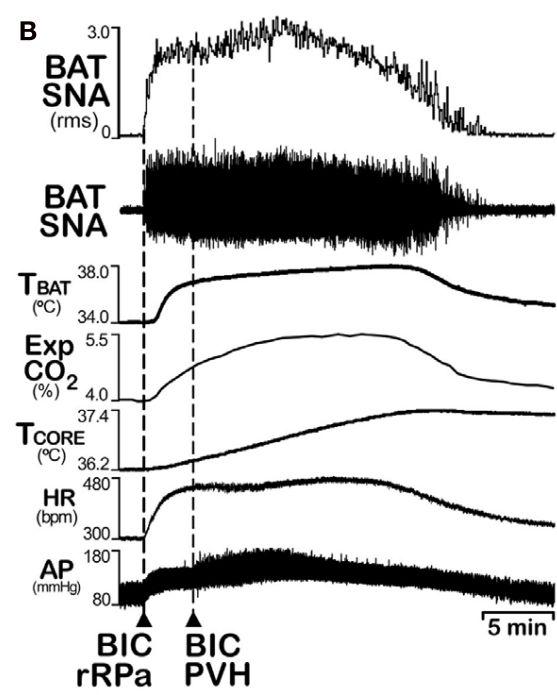

produced by whole body cooling. Core body temperature (TCORE) was also reduced; heart rate $(H R)$ and arterial pressure (AP) were increased by $\mathrm{BIC}$ in PVH. (B) The increases in BAT SNA, TBAT, expired $\mathrm{CO}_{2}, \mathrm{TCORE}, \mathrm{HR}$, and $\mathrm{AP}$ evoked by nanoinjection of $\mathrm{BIC}$ into the $\mathrm{RPa}$ are not affected by nanoinjection of $\mathrm{BIC}$ into the PVH. Modified with permission from Madden and Morrison (2009).

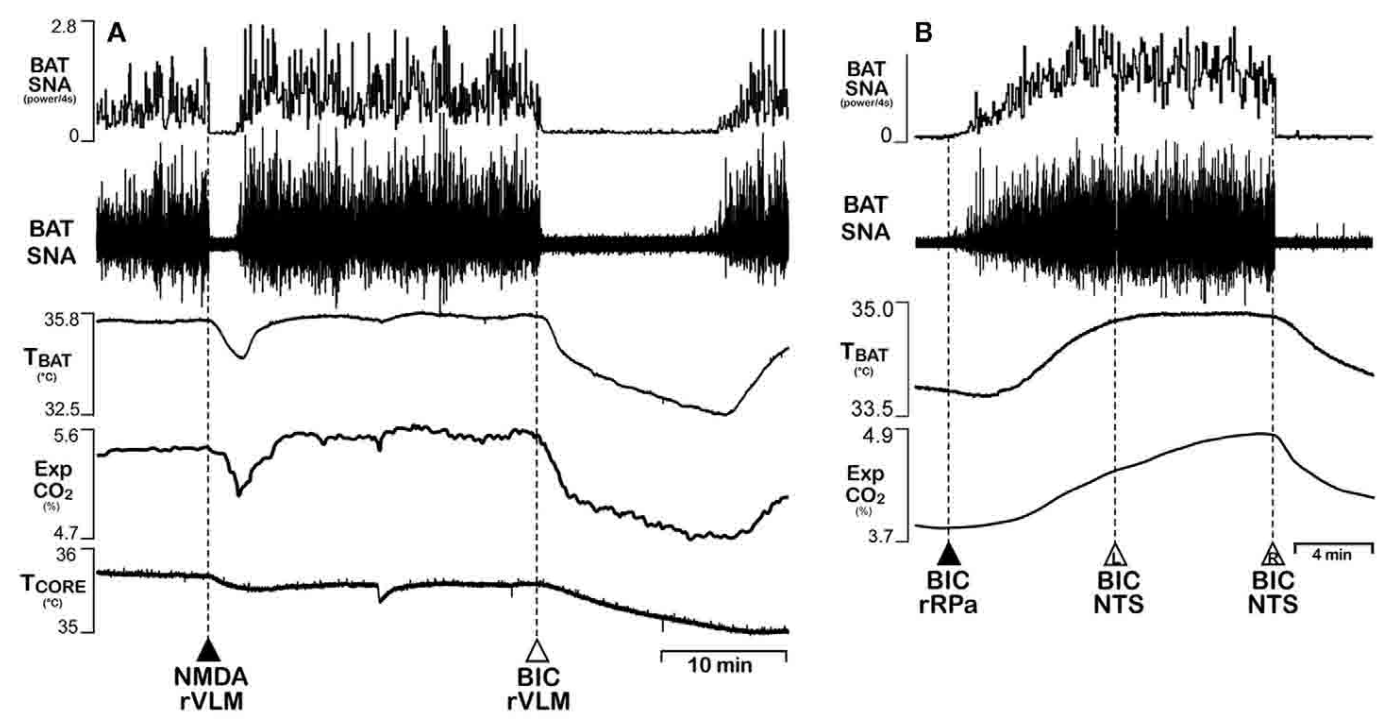

FIGURE 7 | Activation of neurons in the ventrolateral medulla (VLM) or in the nucleus of the solitary tract (NTS) inhibits BAT sympathetic nerve activity (SNA) and BAT thermogenesis. (A) Cooling-evoked increases in BAT SNA, BAT temperature (TBAT), and expired $\mathrm{CO}_{2}\left(\operatorname{Exp~} \mathrm{CO}_{2}\right)$ were reversed following unilateral nanoinjection of either the glutamate receptor agonist, NMDA, or the GABAA receptor antagonist, bicuculline (BIC), into the rostral VLM (RVLM). Core temperature (TCORE) was also reduced by activation of RVLM neurons. (B) Increases in BAT SNA, TBAT, and ExpCO ${ }_{2}$ evoked by BIC nanoinjection into the rostral raphe pallidus ( $\mathrm{rRPa}$ ) were reversed by bilateral nanoinjections of BIC into the medial NTS. Modified with permission from Cao et al. (2010). 
the rRPa, or to pontomedullary transection (Cao et al., 2010). The VLM region from which inhibitions of BAT SNA could be evoked corresponds to the locations of the $\mathrm{A} 1$ and $\mathrm{C} 1$ cell groups in the region ventral to the nucleus ambiguous. Similar inhibitions of BAT SNA were also produced by bilateral injections of bicuculline into the medial NTS (Figure 7B). However, application of leptin and TRH into the NTS elicits increases in BAT temperature (Hermann et al., 2006). Whether the inhibitions of BAT thermogenesis evoked throughout this rostro-caudal extent of the VLM represent activation of a homogeneous inhibitory mechanism or stimulations of different mechanisms at different rosto-caudal levels remains to be determined, as do the mechanisms through which the VLM and the NTS inhibitions of BAT SNA is effected and the physiological circumstances under which such inhibitions of BAT thermogenesis would normally be elicited. In this regard, both hypoxia and hypoglycemia are strong inhibitory signals for BAT thermogenesis (see above) and the commissural NTS contains second-order chemoreceptor sensory neurons mediating an inhibition of BAT SNA (Madden and Morrison, 2005), and the VLM contains neurons sensitive to glucopenia (Ritter et al., 2001), which also inhibits BAT SNA (Madden and Morrison, 2008b).

\section{SUMMARY}

Brown adipose tissue thermogenesis is regulated primarily by a core thermoregulatory neural network which responds to the feedforward afferent signals from cutaneous and core body thermoreceptors and to feedback signals from brain thermosensitive neurons to alter the level of activation of the sympathetic outflow to BAT. We have summarized the research leading to a model (Figure 1) of the thermoregulatory reflex pathway through

\section{REFERENCES}

Almeida, M. C., Steiner, A. A., Branco, L. G., and Romanovsky, A. A. (2006). Neural substrate of cold-seeking behavior in endotoxin shock. PLoS ONE 1, el. doi:10.1371/journal.pone.0000001

Amini-Sereshki, L., and Zarrindast, M. R. (1984). Brain stem tonic inhibition of thermoregulation in the rat. Am. J. Physiol. 247, R154-R159.

Andrew, D., and Craig, A. D. (2001). Spinothalamic lamina I neurons selectively sensitive to histamine: a central neural pathway for itch. Nat. Neurosci. 4, 72-77.

Bacon, S. J., and Smith, A. D. (1988). Preganglionic sympathetic neurones innervating the rat adrenal medulla: immunocytochemical evidence of synaptic input from nerve terminals containing substance P, GABA or 5hydroxytryptamine. J. Auton. Nerv. Syst. 24, 97-122.

Balthasar, N., Dalgaard, L. T., Lee, C. E., Yu, J., Funahashi, H., Williams, T., Ferreira, M., Tang, V., Mcgovern, R. A., Kenny, C. D., Christiansen, L. M., Edelstein, E., Choi, B., Boss,

which environmental cold stimulates thermogenesis and includes the influence on this thermoregulatory network of the pyrogenic mediator, $\mathrm{PGE}_{2}$, to increase body temperature during fever. The cold thermal afferent circuit from cutaneous thermal receptors, through second-order thermosensory neurons in the dorsal horn of the spinal cord ascends to activate neurons in the LPBel which drive GABAergic interneurons in the MnPO to inhibit warm-sensitive, inhibitory output neurons of the MPO. Through the resulting disinhibition of thermogenesis-promoting neurons in the DMH, BAT sympathetic premotor neurons in the rostral ventromedial medulla, including the $\mathrm{rRPa}$, are stimulated to increase the excitation to and responsiveness of the spinal circuits controlling BAT SPN discharge to drive BAT thermogenesis.

Hypoxia and hypoglycemia are strong metabolic regulators of BAT thermogenesis. The activity of neurons in several brain regions can influence the level of BAT thermogenesis and thus could modulate the thermoregulatory control of BAT, although their discharge does not appear to be required to mediate the skin cooling-evoked stimulation of BAT thermogenesis. These include an orexinergic excitation of BAT thermogenesis from neurons in the PeF-LH and inhibitory regulation of BAT thermogenesis by neurons in the PVH, the pontine retrorubral field, the VLM and the NTS.

\section{ACKNOWLEDGMENTS}

Support of the research that contributed to this review came from National Institutes of Health grants R01NS40987 (Shaun F. Morrison), R01DK57838 (Shaun F. Morrison), F32DK065401 (Christopher J. Madden), R56DK082558 (Christopher J. Madden), and an American Heart Association Scientist Development Grant (Christopher J. Madden).

regulation. Histochem. Cell Biol. 123, 147-156.

Blatteis, C. M., and Banet, M. (1986). Autonomic thermoregulation after separation of the preoptic area from the hypothalamus in rats. Pflugers Arch. 406, 480-484.

Boulant, J. A. (2006a). Counterpoint: Heat-induced membrane depolarization of hypothalamic neurons: an unlikely mechanism of central thermosensitivity. Am. J. Physiol. Regul. Integr. Comp. Physiol. 290, R14811484; discussion R1484.

Boulant, J. A. (2006b). Neuronal basis of Hammel's model for set-point thermoregulation. J. Appl. Physiol. 100, 1347-1354.

Boulant, J. A., and Dean, J. B. (1986). Temperature receptors in the central nervous system. Annu. Rev. Physiol. 48, 639-654.

Boulant, J. A., and Hardy, J. D. (1974). The effect of spinal and skin temperatures on the firing rate and thermosensitivity of preoptic neurones. J. Physiol. (Lond.) 240, 639-660.

Bratincsak, A., and Palkovits, M. (2004). Activation of brain areas in rat following warm and cold ambient exposure. Neuroscience 127, 385-397.

Bratincsak, A., and Palkovits, M. (2005). Evidence that peripheral rather than intracranial thermal signals induce thermoregulation. Neuroscience 135, 525-532.

Buchanan, T. A., Cane, P., Eng, C. C., Sipos, G. F., and Lee, C. (1991). Hypothermia is critical for survival during prolonged insulin-induced hypoglycemia in rats. Metab. Clin. Exp. 40, 330-334.

Caldeira, J. C., Franci, C. R., and Pela, I. R. (1998). Bilateral lesion of hypothalamic paraventricular nucleus abolishes fever induced by endotoxin and bradykinin in rats. Ann. N. Y. Acad. Sci. 856, 294-297.

Cammack, C., and Logan, S. D. (1996). Excitation of rat sympathetic preganglionic neurones by selective activation of the NK1 receptor. $J$. Auton. Nerv. Syst. 57, 87-92.

Cannon, B., and Nedergaard, J. (2004). Brown adipose tissue: function and physiological significance. Physiol. Rev. 84, 277-359. 
Cano, G., Passerin, A. M., Schiltz, J. C., Card, J. P., Morrison, S. F., and Sved, A. F. (2003). Anatomical substrates for the central control of sympathetic outflow to interscapular adipose tissue during cold exposure. $J$. Comp. Neurol. 460, 303-326.

Cao, W. H., Fan, W., and Morrison, S. F. (2004). Medullary pathways mediating specific sympathetic responses to activation of dorsomedial hypothalamus. Neuroscience 126, 229-240.

Cao, W. H., Madden, C. J., and Morrison, S. F. (2010). Inhibition of brown adipose tissue thermogenesis by neurons in the ventrolateral medulla and in the nucleus tractus solitarius. Am. J. Physiol. Regul. Integr. Comp. Physiol. 299, R277R290.

Cao, W. H., and Morrison, S. F. (2005). Brown adipose tissue thermogenesis contributes to fentanyl-evoked hyperthermia. Am. J. Physiol. Regul. Integr. Comp. Physiol. 288, R723R732.

Cao, W. H., and Morrison, S. F. (2006). Glutamate receptors in the raphe pallidus mediate brown adipose tissue thermogenesis evoked by activation of dorsomedial hypothalamic neurons. Neuropharmacology 51, 426-437.

Caterina, M. J., Leffler, A., Malmberg, A. B., Martin, W. J., Trafton, J., PetersenZeitz, K. R., Koltzenburg, M., Basbaum, A. I., and Julius, D. (2000). Impaired nociception and pain sensation in mice lacking the capsaicin receptor. Science 288, 306-313.

Cerri, M., and Morrison, S. F. (2005). Activation of lateral hypothalamic neurons stimulates brown adipose tissue thermogenesis. Neuroscience 135, 627-638.

Cerri, M., and Morrison, S. F. (2006). Corticotropin releasing factor increases in brown adipose tissue thermogenesis and heart rate through dorsomedial hypothalamus and medullary raphe pallidus. Neuroscience 140, 711-721.

Chen, X. M., Hosono, T., Yoda, T., Fukuda, Y., and Kanosue, K. (1998). Efferent projection from the preoptic area for the control of non-shivering thermogenesis in rats. J. Physiol. (Lond.) 512( $\mathrm{Pt} \mathrm{3),}$ 883-892.

Chen, X. M., Nishi, M., Taniguchi, A., Nagashima, K., Shibata, M., and Kanosue, K. (2002). The caudal periaqueductal gray participates in the activation of brown adipose tissue in rats. Neurosci. Lett. 331, 17-20.

Christensen, C. R., Clark, P. B., and Morton, K. A. (2006). Reversal of hypermetabolic brown adipose tissue in
F-18 FDG PET imaging. Clin. Nucl. Med. 31, 193-196.

Clapham, J. C. (2011). Central control of thermogenesis. Neuropharmacology doi: 10.1016/j.neuropharm.2011.10.014. [Epub ahead of print].

Colburn, R. W., Lubin, M. L., Stone, D. J. Jr., Wang, Y., Lawrence, D., D’andrea, M. R., Brandt, M. R., Liu, Y., Flores, C. M., and Qin, N. (2007). Attenuated cold sensitivity in TRPM8 null mice. Neuron 54, 379-386.

Conte, D., Deuchars, S. A., and Deuchars, J. (2007). Do serotonin immunoreactive terminals innervate GABAergic neurons in the central autonomic area of the mouse spinal cord. FASEB J. 21, A885.

Coote, J. H., Macleod, V. H., FleetwoodWalker, S., and Gilbey, M. P. (1981). The response of individual sympathetic preganglionic neurones to microelectrophoretically applied endogenous monoamines. Brain Res. 215, 135-145.

Cowley, M. A., Pronchuk, N., Fan, W., Dinulescu, D. M., Colmers, W. F., and Cone, R. D. (1999). Integration of NPY, AGRP, and melanocortin signals in the hypothalamic paraventricular nucleus: evidence of a cellular basis for the adipostat. Neuron 24, 155-163.

Craig, A. D. (2002). How do you feel? Interoception: the sense of the physiological condition of the body. Nat. Rev. Neurosci. 3, 655-666.

Craig, A. D., Bushnell, M. C., Zhang, E. T., and Blomqvist, A. (1994). A thalamic nucleus specific for pain and temperature sensation. Nature 372, 770-773.

Craig, A. D., Krout, K., and Andrew, D. (2001). Quantitative response characteristics of thermoreceptive and nociceptive lamina I spinothalamic neurons in the cat. J. Neurophysiol. 86, 1459-1480.

Cypess, A. M., Lehman, S., Williams, G., Tal, I., Rodman, D., Goldfine, A. B., Kuo, F. C., Palmer, E. L., Tseng, Y. H., Doria, A., Kolodny, G. M., and Kahn, C. R. (2009). Identification and importance of brown adipose tissue in adult humans. N. Engl. J. Med. 360, 1509-1517.

de Lecea, L., Kilduff, T. S., Peyron, C., Gao, X., Foye, P. E., Danielson, P. E., Fukuhara, C., Battenberg, E. L., Gautvik, V. T., Bartlett, F. S. II, Frankel, W. N., Van Den Pol, A. N., Bloom, F. E., Gautvik, K. M., and Sutcliffe, J. G. (1998). The hypocretins: hypothalamus-specific peptides with neuroexcitatory activity. Proc. Natl. Acad. Sci. U.S.A. 95, 322-327. de Menezes, R. C., Zaretsky, D. V., Fontes, M. A., and Dimicco, J. A. (2009). Cardiovascular and thermal responses evoked from the periaqueductal grey require neuronal activity in the hypothalamus. J. Physiol. (Lond.) 587, 1201-1215.

Deuchars, S. A., Milligan, C. J., Stornetta, R. L., and Deuchars, J. (2005). GABAergic neurons in the central region of the spinal cord: a novel substrate for sympathetic inhibition. J. Neurosci. 25, 1063-1070.

Deuchars, S. A., Spyer, K. M., and Gilbey, M. P. (1997). Stimulation within the rostral ventrolateral medulla can evoke monosynaptic GABAergic IPSPs in sympathetic preganglionic neurons in vitro. J. Neurophysiol. 77, 229-235.

Dhaka, A., Murray, A. N., Mathur, J., Earley, T. J., Petrus, M. J., and Patapoutian, A. (2007). TRPM8 is required for cold sensation in mice. Neuron 54, 371-378.

Dib, B. (1987). Thermoregulatory behaviour induced by intrathecal injection of substance $\mathrm{P}$ in the rat Eur. J. Pharmacol. 133, 147-153.

Dimicco, J. A., and Zaretsky, D. V. (2007). The dorsomedial hypothalamus: a new player in thermoregulation. Am. J. Physiol. Regul. Integr. Comp. Physiol. 292, R47-R63.

Egawa, M., Yoshimatsu, H., and Bray, G. A. (1989a). Effects of 2-deoxy-Dglucose on sympathetic nerve activity to interscapular brown adipose tissue. Am. J. Physiol. 257, R1377R1385.

Egawa, M., Yoshimatsu, H., and Bray, G. A. (1989b). Lateral hypothalamic injection of 2-deoxy-D-glucose suppresses sympathetic activity. Am. J. Physiol. 257, R1386-R1392.

Egawa, M., Yoshimatsu, H., and Bray, G. A. (1991). Neuropeptide Y suppresses sympathetic activity to interscapular brown adipose tissue in rats. Am. J. Physiol. 260, R328-R334.

Elmquist, J. K., Scammell, T. E., Jacobson, C. D., and Saper, C. B. (1996). Distribution of Fos-like immunoreactivity in the rat brain following intravenous lipopolysaccharide administration. J. Comp. Neurol. 371, 85-103.

Elmquist, J. K., Scammell, T. E., and Saper, C. B. (1997). Mechanisms of CNS response to systemic immune challenge: the febrile response. Trends Neurosci. 20, 565-570.

Fan, W., Morrison, S. F., Cao, W. H. and Yu, P. (2007). Thermogenesis activated by central melanocortin signaling is dependent on neurons in the rostral raphe pallidus ( $\mathrm{rRPa}$ ) area. Brain Res. 1179, 61-69.
Freinkel, N., Metzger, B. E., Harris, E., Robinson, S., and Mager, M. (1972). The hypothermia of hypoglycemia. Studies with 2-deoxy-D-glucose in normal human subjects and mice. $N$. Engl. J. Med. 287, 841-845.

Gavva, N. R., Bannon, A. W., Surapaneni, S., Hovland, D. N. Jr., Lehto, S. G., Gore, A., Juan, T., Deng, H., Han, B., Klionsky, L., Kuang, R., Le, A., Tamir, R., Wang, J., Youngblood, B., Zhu, D., Norman, M. H., Magal, E., Treanor, J. J., and Louis, J. C. (2007). The vanilloid receptor TRPV1 is tonically activated in vivo and involved in body temperature regulation. J. Neurosci. 27, 3366-3374.

Golozoubova, V., Cannon, B., and Nedergaard, J. (2006). UCP1 is essential for adaptive adrenergic nonshivering thermogenesis. Am. J. Physiol. Endocrinol. Metab. 291, E350-E357.

Guieu, J. D., and Hardy, J. D. (1970). Effects of heating and cooling of the spinal cord on preoptic unit activity. J. Appl. Physiol. 29, 675-683.

Gupta, B. N., Nier, K., and Hensel, H. (1979). Cold-sensitive afferents from the abdomen. Pflugers Arch. 380, 203-204

Hany, T. F., Gharehpapagh, E., Kamel, E. M., Buck, A., Himms-Hagen, J., and Von Schulthess, G. K. (2002). Brown adipose tissue: a factor to consider in symmetrical tracer uptake in the neck and upper chest region. Eur. J. Nucl. Med. Mol. Imaging 29, 1393-1398.

Hara, J., Yanagisawa, M., and Sakurai, T. (2005). Difference in obesity phenotype between orexin-knockout mice and orexin neuron-deficient mice with same genetic background and environmental conditions. Neurosci. Lett. 380, 239-242.

Hermann, D. M., Luppi, P. H., Peyron, C., Hinckel, P., and Jouvet, M. (1997). Afferent projections to the rat nuclei raphe magnus, raphe pallidus and reticularis gigantocellularis pars alpha demonstrated by iontophoretic application of choleratoxin (subunit b). J. Chem. Neuroanat. 13, 1-21.

Hermann, G. E., Barnes, M. J., and Rogers, R. C. (2006). Leptin and thyrotropin-releasing hormone: cooperative action in the hindbrain to activate brown adipose thermogenesis. Brain Res. 1117, 118-124.

Hetherington, A. W., and Ranson, S. W. (1940). Hypothalamic lesions and adiposity in the rat. Anat. Rec. 78, 149-172.

Hodges, M. R., Tattersall, G. J., Harris, M. B., Mcevoy, S. D., Richerson, D. N., Deneris, E. S., Johnson, R. L., Chen, Z. F., and Richerson, 
G. B. (2008). Defects in breathing and thermoregulation in mice with near-complete absence of central serotonin neurons. J. Neurosci. 28, 2495-2505.

Hori, T. (1984). Capsaicin and central control of thermoregulation. Pharmacol. Ther. 26, 389-416.

Horn, T., Wilkinson, M. F., Landgraf, R., and Pittman, Q. J. (1994). Reduced febrile responses to pyrogens after lesions of the hypothalamic paraventricular nucleus. Am. J. Physiol. 267, R323-R328.

Hylden, J. L., Anton, F., and Nahin, R. L. (1989). Spinal lamina I projection neurons in the rat: collateral innervation of parabrachial area and thalamus. Neuroscience 28, 27-37.

Imai-Matsumura, K., Matsumura, K., and Nakayama, T. (1984). Involvement of ventromedial hypothalamus in brown adipose tissue thermogenesis induced by preoptic cooling in rats. Jpn. J. Physiol. 34, 939-943.

Ishiwata, T., Saito, T., Hasegawa, H., Yazawa, T., Kotani, Y., Otokawa, M., and Aihara, Y. (2005). Changes of body temperature and thermoregulatory responses of freely moving rats during GABAergic pharmacological stimulation to the preoptic area and anterior hypothalamus in several ambient temperatures. Brain Res. 1048, 32-40.

Jancso-Gabor, A., Szolcsanyi, J., and Jancso, N. (1970). Irreversible impairment of thermoregulation induced by capsaicin and similar pungent substances in rats and guinea-pigs. J. Physiol. (Lond.) 206, 495-507.

Klockener, T., Hess, S., Belgardt, B. F., Paeger, L., Verhagen, L. A., Husch, A., Sohn, J. W., Hampel, B., Dhillon, H., Zigman, J. M., Lowell, B. B., Williams, K. W., Elmquist, J. K., Horvath, T. L., Kloppenburg, P., and Bruning, J. C. (2011). High-fat feeding promotes obesity via insulin receptor/PI3Kdependent inhibition of SF-1 VMH neurons. Nat. Neurosci. 14, 911-918.

Kobayashi, A., and Osaka, T. (2003). Involvement of the parabrachial nucleus in thermogenesis induced by environmental cooling in the rat. Pflugers Arch. 446, 760-765.

Kobayashi, S., Hori, A., Matsumura, K., and Hosokawa, H. (2006). Point: heat-induced membrane depolarization of hypothalamic neurons: a putative mechanism of central thermosensitivity. Am. J. Physiol. Regul. Integr. Comp. Physiol. 290, R1479R1480; discussion R1484.

Kok, S. W., Overeem, S., Visscher, T. L., Lammers, G. J., Seidell, J. C.,
Pijl, H., and Meinders, A. E. (2003). Hypocretin deficiency in narcoleptic humans is associated with abdominal obesity. Obes. Res. 11, 1147-1154.

Lazarus, M., Yoshida, K., Coppari, R., Bass, C. E., Mochizuki, T., Lowell, B. B., and Saper, C. B. (2007). EP3 prostaglandin receptors in the median preoptic nucleus are critical for fever responses. Nat. Neurosci. 10, 1131-1133.

Lee, H., Iida, T., Mizuno, A., Suzuki, M., and Caterina, M. J. (2005). Altered thermal selection behavior in mice lacking transient receptor potential vanilloid 4. J. Neurosci. 25, 1304-1310.

Li, J., Xiong, K., Pang, Y., Dong, Y., Kaneko, T., and Mizuno, N. (2006). Medullary dorsal horn neurons providing axons to both the parabrachial nucleus and thalamus. J. Comp. Neurol. 498, 539-551.

Lomax, P., Malveaux, E., and Smith, R. E. (1964). Brain temperatures in the rat during exposure to low environmental temperatures. Am. J. Physiol. 207, 736-739.

Lopez, M., Varela, L., Vazquez, M. J., Rodriguez-Cuenca, S., Gonzalez, C. R., Velagapudi, V. R., Morgan, D. A., Schoenmakers, E., Agassandian, K., Lage, R., Martinez De Morentin, P. B., Tovar, S., Nogueiras, R., Carling, D., Lelliott, C., Gallego, R., Oresic, M., Chatterjee, K., Saha, A. K., Rahmouni, K., Dieguez, C., and Vidal-Puig, A. (2010). Hypothalamic AMPK and fatty acid metabolism mediate thyroid regulation of energy balance. Nat. Med. 16, 1001-1008.

Lu, J., Zhang, Y. H., Chou, T. C., Gaus, S. E., Elmquist, J. K., Shiromani, P., and Saper, C. B. (2001). Contrasting effects of ibotenate lesions of the paraventricular nucleus and subparaventricular zone on sleep-wake cycle and temperature regulation. $J$. Neurosci. 21, 4864-4874.

Lundius, E. G., Sanchez-Alavez, M., Ghochani, Y., Klaus, J., and Tabarean, I. V. (2010). Histamine influences body temperature by acting at $\mathrm{H} 1$ and $\mathrm{H} 3$ receptors on distinct populations of preoptic neurons. J. Neurosci. 30, 4369-4381.

Madden, C. J. (2012). Glucoprivation in the ventrolateral medulla decreases brown adipose tissue sympathetic nerve activity by decreasing the activity of neurons in raphe pallidus. Am. J. Physiol. Regul. Integr. Comp. Physiol. 302, R224-R232.

Madden, C. J., and Morrison, S. F. (2003). Excitatory amino acid receptor activation in the raphe pallidus area mediates prostaglandin-evoked thermogenesis. Neuroscience 122, 5-15.

Madden, C. J., and Morrison, S. F. (2004). Excitatory amino acid receptors in the dorsomedial hypothalamus mediate prostaglandin-evoked thermogenesis in brown adipose tissue. Am. J. Physiol. Regul. Integr. Comp. Physiol. 286, R320-R325.

Madden, C. J., and Morrison, S. F. (2005). Hypoxic activation of arterial chemoreceptors inhibits sympathetic outflow to brown adipose tissue in rats. J. Physiol. 566, 559-573.

Madden, C. J., and Morrison, S. F. (2006). Serotonin potentiates sympathetic responses evoked by spinal NMDA. J. Physiol. (Lond.) 577, 525-537.

Madden, C. J., and Morrison, S. F. (2008a). Brown adipose tissue sympathetic nerve activity is potentiated by activation of 5-hydroxytryptamine (5$\mathrm{HT})(1 \mathrm{~A}) / 5-\mathrm{HT}(7)$ receptors in the rat spinal cord. Neuropharmacology 54, 487-496.

Madden, C. J., and Morrison, S. F. (2008b). Neural circuits involved in glucoprivation-evoked inhibition of metabolism in brown adipose tissue (BAT). FASEB J. 22, 950-958.

Madden, C. J., and Morrison, S. F (2009). Neurons in the paraventricular nucleus of the hypothalamus inhibit sympathetic outflow to brown adipose tissue. Am. J. Physiol. Regul. Integr. Comp. Physiol. 296 , R831-R843.

Madden, C. J., and Morrison, S. F. (2010). Endogenous activation of spinal 5-hydroxytryptamine (5-HT) receptors contributes to the thermoregulatory activation of brown adipose tissue. Am. J. Physiol Regul. Integr. Comp. Physiol. 298, R776-R783.

Mager, M., Robinson, S., and Freinkel, N. (1976). Drug modification of hypothermia induced by CNS glucopenia in the mouse. J. Appl. Physiol. 41, 559-564.

Martin-Cora, F. J., Fornal, C. A., Metzler, C. W., and Jacobs, B. L. (2000). Single-unit responses of serotonergic medullary and pontine raphe neurons to environmental cooling in freely moving cats. Neuroscience 98 , 301-309.

Matsumura, K., Cao, C., Ozaki, M., Morii, H., Nakadate, K., and Watanabe, Y. (1998). Brain endothelial cells express cyclooxygenase-2 during lipopolysaccharideinduced fever: light and electron microscopic immunocytochemical studies. J. Neurosci. 18 6279-6289.
McKemy, D. D., Neuhausser, W. M., and Julius, D. (2002). Identification of a cold receptor reveals a general role for TRP channels in thermosensation. Nature 416, 52-58.

Minokoshi, Y., Saito, M., and Shimazu, T. (1986). Sympathetic denervation impairs responses of brown adipose tissue to VMH stimulation. Am. J. Physiol. 251, R1005-R1008.

Miyazaki, T., Coote, J. H., and Dun, N. J. (1989). Excitatory and inhibitory effects of epinephrine on neonatal rat sympathetic preganglionic neurons in vitro. Brain Res. 497, 108-116.

Monda, M., Viggiano, A., Mondola, P., and De Luca, V. (2001). Inhibition of prostaglandin synthesis reduces hyperthermic reactions induced by hypocretin-1/orexin A. Brain Res. 909, 68-74.

Moqrich, A., Hwang, S. W., Earley, T. J., Petrus, M. J., Murray, A. N., Spencer, K. S., Andahazy, M., Story, G. M., and Patapoutian, A. (2005). Impaired thermosensation in mice lacking TRPV3, a heat and camphor sensor in the skin. Science 307 1468-1472.

Morrison, S. F. (1999). RVLM and raphe differentially regulate sympathetic outflows to splanchnic and brown adipose tissue. Am. J. Physiol. 276, R962-R973.

Morrison, S. F. (2003). Raphe pallidus neurons mediate prostaglandin E2evoked increases in brown adipose tissue thermogenesis. Neuroscience 121, 17-24.

Morrison, S. F. (2004). Activation of 5-HT1A receptors in raphe pallidus inhibits leptin-evoked increases in brown adipose tissue thermogenesis. Am. J. Physiol. Regul. Integr. Comp. Physiol. 286, R832-R837.

Morrison, S. F. (2011). 2010 Carl Ludwig distinguished lectureship of the APS neural control and autonomic regulation section: central neural pathways for thermoregulatory cold defense. J. Appl. Physiol. 110, 1137-1149.

Morrison, S. F., and Blessing, W. W. (2011). "Central nervous system regulation of body temperature," in Central Regulation of Autonomic Functions, 2nd Edn, eds I. J. Llewellyn-Smith and A. J. M. Verberne (New York: Oxford University Press), 324-344.

Morrison, S. F., Cao, W.-H., and Madden, C. J. (2004). Dorsomedial hypothalamic and brainstem pathways controlling thermogenesis in brown adipose tissue. J. Therm. Biol. 29, 333-337. 
Morrison, S. F., Sved, A. F., and Passerin, A. M. (1999). GABA-mediated inhibition of raphe pallidus neurons regulates sympathetic outflow to brown adipose tissue. Am. J. Physiol. 276, R290-R297.

Nakamura, K., Kaneko, T., Yamashita, Y., Hasegawa, H., Katoh, H., and Negishi, M. (2000). Immunohistochemical localization of prostaglandin EP3 receptor in the rat nervous system. J. Comp. Neurol. 421, 543-569.

Nakamura, K., Matsumura, K., Hubschle, T., Nakamura, Y., Hioki, H., Fujiyama, F., Boldogkoi, Z., Konig, M., Thiel, H. J., Gerstberger, R., Kobayashi, S., and Kaneko, T. (2004a). Identification of sympathetic premotor neurons in medullary raphe regions mediating fever and other thermoregulatory functions. J. Neurosci. 24, 5370-5380.

Nakamura, K., Wu, S. X., Fujiyama, F., Okamoto, K., Hioki, H., and Kaneko, T. (2004b). Independent inputs by VGLUT2- and VGLUT3positive glutamatergic terminals onto rat sympathetic preganglionic neurons. Neuroreport 15, 431-436.

Nakamura, K., Matsumura, K., Kaneko, T., Kobayashi, S., Katoh, H., and Negishi, M. (2002). The rostral raphe pallidus nucleus mediates pyrogenic transmission from the preoptic area. J. Neurosci. 22, 4600-4610.

Nakamura, K., and Morrison, S. F. (2007). Central efferent pathways mediating skin cooling-evoked sympathetic thermogenesis in brown adipose tissue. Am. J. Physiol. Regul. Integr. Comp. Physiol. 292, R127R136.

Nakamura, K., and Morrison, S. F. (2008a). Preoptic mechanism for cold-defensive responses to skin cooling. J. Physiol. (Lond.) 586, 2611-2620.

Nakamura, K., and Morrison, S. F. (2008b). A thermosensory pathway that controls body temperature. Nat. Neurosci. 11, 62-71.

Nakamura, K., and Morrison, S. F. (2010). A thermosensory pathway mediating heat-defense responses. Proc. Natl. Acad. Sci. U.S.A. 107, 8848-8853.

Nakamura, Y., Nakamura, K., Matsumura, K., Kobayashi, S., Kaneko, T., and Morrison, S. F. (2005). Direct pyrogenic input from prostaglandin EP3 receptor-expressing preoptic neurons to the dorsomedial hypothalamus. Eur. J. Neurosci. 22, 3137-3146.
Nakamura, Y., Nakamura, K., and Morrison, S. F. (2009). Different populations of prostaglandin EP3 receptorexpressing preoptic neurons project to two fever-mediating sympathoexcitatory brain regions. Neuroscience 161, 614-620.

Nakayama, T., Eisenman, J. S., and Hardy, J. D. (1961). Single unit activity of anterior hypothalamus during local heating. Science 134, 560-561.

Nakayama, T., Hammel, H., Hardy, J., and Eisenman, J. (1963). Thermal stimulation of electrical activity of single units of the preoptic region. Am. J. Physiol. 204, 1122-1126.

Narumiya, S., Sugimoto, Y., and Ushikubi, F. (1999). Prostanoid receptors: structures, properties, and functions. Physiol. Rev. 79, 1193-1226.

Nason, M. W. Jr., and Mason, P. (2006). Medullary raphe neurons facilitate brown adipose tissue activation. $J$. Neurosci. 26, 1190-1198.

Nautiyal, K. M., Dailey, M., Brito, N., Brito, M. N., Harris, R. B., Bartness, T. J., and Grill, H. J. (2008). Energetic responses to cold temperatures in rats lacking forebrain-caudal brain stem connections. Am. J. Physiol. Regul. Integr. Comp. Physiol. 295, R789-R798.

Nedergaard, J., Bengtsson, T., and Cannon, B. (2007). Unexpected evidence for active brown adipose tissue in adult humans. Am. J. Physiol. Endocrinol. Metab. 293, E444-E452.

Nguyen, K. D., Qiu, Y., Cui, X., Goh, Y. P., Mwangi, J., David, T., Mukundan, L., Brombacher, F., Locksley, R. M., and Chawla, A. (2011). Alternatively activated macrophages produce catecholamines to sustain adaptive thermogenesis. Nature 480, 104-108.

Niijima, A. (1999). Reflex effects from leptin sensors in the white adipose tissue of the epididymis to the efferent activity of the sympathetic and vagus nerve in the rat. Neurosci. Lett. 262, 125-128.

Niijima, A., Rohner-Jeanrenaud, F., and Jeanrenaud, B. (1984). Role of ventromedial hypothalamus on sympathetic efferents of brown adipose tissue. Am. J. Physiol. 247, R650-R654.

Oldfield, B. J., Giles, M. E., Watson, A., Anderson, C., Colvill, L. M., and Mckinley, M. J. (2002). The neurochemical characterisation of hypothalamic pathways projecting polysynaptically to brown adipose tissue in the rat. Neuroscience 110, 515-526.

Ootsuka, Y., Blessing, W. W., Steiner, A. A., and Romanovsky, A. A. (2008).
Fever response to intravenous prostaglandin E2 is mediated by the brain but does not require afferent vagal signaling. Am. J. Physiol. Regul. Integr. Comp. Physiol. 294 R1294-R303

Ootsuka, Y., De Menezes, R. C., Zaretsky, D. V., Alimoradian, A., Hunt, J., Stefanidis, A., Oldfield, B. J., and Blessing, W. W. (2009). Brown adipose tissue thermogenesis heats brain and body as part of the brain-coordinated ultradian basic rest-activity cycle. Neuroscience 164 849-861.

Osaka, T. (2004). Thermogenesis elicited by skin cooling in anaesthetized rats: lack of contribution of the cerebral cortex. J. Physiol. (Lond.) 555, 503-513.

Peier, A. M., Moqrich, A., Hergarden, A. C., Reeve, A. J., Andersson, D. A., Story, G. M., Earley, T. J., Dragoni, I., Mcintyre, P., Bevan, S., and Patapoutian, A. (2002). A TRP channel that senses cold stimuli and menthol. Cell 108, 705-715.

Perkins, M. N., Rothwell, N. J., Stock, M. J., and Stone, T. W. (1981). Activation of brown adipose tissue thermogenesis by the ventromedial hypothalamus. Nature 289 , 401-402.

Peyron, C., Tighe, D. K., Van Den Pol, A. N., De Lecea, L., Heller, H. C., Sutcliffe, J. G., and Kilduff, T. S. (1998). Neurons containing hypocretin (orexin) project to multiple neuronal systems. J. Neurosci. 18, 9996-10015.

Plazzi, G., Moghadam, K. K., Maggi, L. S., Donadio, V., Vetrugno, R. Liguori, R., Zoccoli, G., Poli, F., Pizza, F., Pagotto, U., and Ferri, R. (2011). Autonomic disturbances in narcolepsy. Sleep Med. Rev. 15, 187-196.

Ranels, H. J., and Griffin, J. D. (2003). The effects of prostaglandin E2 on the firing rate activity of thermosensitive and temperature insensitive neurons in the ventromedial preoptic area of the rat hypothalamus. Brain Res. 964, 42-50.

Rathner, J. A., and Morrison, S. F. (2006). Rostral ventromedial periaqueductal gray: a source of inhibition of the sympathetic outflow to brown adipose tissue. Brain Res. 1077, 99-107.

Riedel, W. (1976). Warm receptors in the dorsal abdominal wall of the rabbit. Pflugers Arch. 361, 205-206.

Ritter, S., Bugarith, K., and Dinh, T. T. (2001). Immunotoxic destruction of distinct catecholamine subgroups produces selective impairment of glucoregulatory responses and neuronal activation. J. Comp. Neurol. 432, 197-216.

Ritter, S., Li, A. J., Wang, Q., and Dinh, T. T. (2011). Minireview: The value of looking backward: the essential role of the hindbrain in counterregulatory responses to glucose deficit. Endocrinology 152, 4019-4032.

Romanovsky, A. A. (2004). Do fever and anapyrexia exist? Analysis of set point-based definitions. Am. J. Physiol. Regul. Integr. Comp. Physiol. 287, R992-R995.

Romanovsky, A. A. (2007). Thermoregulation: some concepts have changed. Functional architecture of the thermoregulatory system. Am. J. Physiol. Regul. Integr. Comp. Physiol. 292, R37-R46.

Romanovsky, A. A., Almeida, M. C., Garami, A., Steiner, A. A., Norman, M. H., Morrison, S. F., Nakamura, K., Burmeister, J. J., and Nucci, T. B. (2009). The transient receptor potential vanilloid-1 channel in thermoregulation: a thermosensor it is not. Pharmacol. Rev. 61, 228-261.

Rothwell, N. J., Stock, M. J., and Thexton, A. J. (1983). Decerebration activates thermogenesis in the rat. $J$ Physiol. (Lond.) 342, 15-22.

Sakaguchi, T., Bray, G. A., and Eddlestone, G. (1988). Sympathetic activity following paraventricular or ventromedial hypothalamic lesions in rats. Brain Res. Bull. 20, 461-465.

Sakurai, T., Amemiya, A., Ishii, M., Matsuzaki, I., Chemelli, R. M., Tanaka, H., Williams, S. C., Richardson, J. A. Kozlowski, G. P., Wilson, S., Arch, J. R., Buckingham, R. E., Haynes, A. C., Carr, S. A., Annan, R. S., Mcnulty, D. E., Liu, W. S., Terrett, J. A., Elshourbagy, N. A., Bergsma, D. J., and Yanagisawa, M. (1998). Orexins and orexin receptors: a family of hypothalamic neuropeptides and $G$ protein-coupled receptors that regulate feeding behavior. Cell 92, 573-585.

Samuels, B. C., Zaretsky, D. V., and Dimicco, J.A. (2002). Tachycardia evoked by disinhibition of the dorsomedial hypothalamus in rats is mediated through medullary raphe. J. Physiol. (Lond.) 538, 941-946.

Sarkar, S., Zaretskaia, M. V., Zaretsky, D. V., Moreno, M., and Dimicco, J. A. (2007). Stressand lipopolysaccharide-induced cfos expression and nNOS in hypothalamic neurons projecting to medullary raphe in rats: a triple immunofluorescent labeling study. Eur. J. Neurosci. 26, 2228-2238. 
Sasek, C. A., Wessendorf, M. W., and Helke, C. J. (1990). Evidence for coexistence of thyrotropin-releasing hormone, substance $\mathrm{P}$ and serotonin in ventral medullary neurons that project to the intermediolateral cell column in the rat. Neuroscience 35, 105-119.

Scammell, T. E., Elmquist, J. K., Griffin, J. D., and Saper, C. B. (1996). Ventromedial preoptic prostaglandin E2 activates fever-producing autonomic pathways. J. Neurosci. 16, 6246-6254.

Schoener, E. P., and Wang, S. C. (1976). Effects of locally administered prostaglandin E1 on anterior hypothalamic neurons. Brain Res. 117, 157-162.

Sellayah, D., Bharaj, P., and Sikder, D. (2011). Orexin is required for brown adipose tissue development, differentiation, and function. Cell Metab. 14, 478-490.

Shibata, M., Uno, T., and Hashimoto, M. (1999). Disinhibition of lower midbrain neurons enhances non-shivering thermogenesis in anesthetized rats. Brain Res. 833, 242-250.

Skibicka, K. P., Alhadeff, A. L., Leichner, T. M., and Grill, H. J. (2011). Neural controls of prostaglandin 2 pyrogenic, tachycardic, and anorexic actions are anatomically distributed. Endocrinology 152, 2400-2408.

Skibicka, K. P., and Grill, H. J. (2009). Hypothalamic and hindbrain melanocortin receptors contribute to the feeding, thermogenic, and cardiovascular action of melanocortins. Endocrinology 150, 5351-5361.

Soderlund, V., Larsson, S. A., and Jacobsson, H. (2007). Reduction of FDG uptake in brown adipose tissue in clinical patients by a single dose of propranolol. Eur. J. Nucl. Med. Mol. Imaging 34, 1018-1022.

Song, C. K., Schwartz, G. J., and Bartness, T. J. (2009). Anterograde transneuronal viral tract tracing reveals central sensory circuits from white adipose tissue. Am. J. Physiol. Regul. Integr. Comp. Physiol. 296, R501-R511.

Song, C. K., Vaughan, C. H., KeenRhinehart, E., Harris, R. B., Richard, D., and Bartness, T. J. (2008). Melanocortin-4 receptor mRNA expressed in sympathetic outflow neurons to brown adipose tissue: neuroanatomical and functional evidence. Am. J. Physiol. Regul. Integr. Comp. Physiol. 295, R417-R428.

Steiner, A. A., Antunes-Rodrigues, J. and Branco, L. G. (2002). Role of preoptic second messenger systems (cAMP and cGMP) in the febrile response. Brain Res. 944, 135-145.

Steiner, A. A., Turek, V. F., Almeida, M. C., Burmeister, J. J., Oliveira, D. L., Roberts, J. L., Bannon, A. W., Norman, M. H., Louis, J. C., Treanor, J. J., Gavva, N. R., and Romanovsky, A. A. (2007). Nonthermal activation of transient receptor potential vanilloid-1 channels in abdominal viscera tonically inhibits autonomic cold-defense effectors. J. Neurosci. 27, 7459-7468.

Stornetta, R. L., Mcquiston, T. J., and Guyenet, P. G. (2004). GABAergic and glycinergic presympathetic neurons of rat medulla oblongata identified by retrograde transport of pseudorabies virus and in situ hybridization. J. Comp. Neurol. 479, 257-270.

Stornetta, R. L., Rosin, D. L., Simmons, J. R., Mcquiston, T. J., Vujovic, N., Weston, M. C., and Guyenet, P. G. (2005). Coexpression of vesicular glutamate transporter3 and gamma-aminobutyric acidergic markers in rat rostral medullary raphe and intermediolateral cell column. J. Comp. Neurol. 492, 477-494.

Szelenyi, Z., Hummel, Z., Szolcsanyi, J., and Davis, J. B. (2004). Daily body temperature rhythm and heat tolerance in TRPV1 knockout and capsaicin pretreated mice. Eur. J. Neurosci. 19, 1421-1424.

Tominaga, M., Caterina, M. J., Malmberg, A. B., Rosen, T. A., Gilbert, H., Skinner, K., Raumann, B. E. Basbaum, A. I., and Julius, D. (1998). The cloned capsaicin receptor integrates multiple pain-producing stimuli. Neuron 21, 531-543.

Tupone, D., Madden, C. J., Cano, G., and Morrison, S. F. (2011). An orexinergic projection from perifornical hypothalamus to raphe pallidus increases rat brown adipose tissue thermogenesis. J. Neurosci. 31, 15944-15955.

Uschakov, A., Gong, H., Mcginty, D. and Szymusiak, R. (2007). Efferent projections from the median preoptic nucleus to sleep- and arousalregulatory nuclei in the rat brain. Neuroscience 150, 104-120. van Marken Lichtenbelt, W. D., Vanhommerig, J. W., Smulders, N. M., Drossaerts, J. M., Kemerink, G. J., Bouvy, N. D., Schrauwen, P., and Teule, G. J. (2009). Cold-activated brown adipose tissue in healthy men. N. Engl. J. Med. 360, 1500-1508.

Vera, P. L., Holets, V. R., and Miller, K. E. (1990). Ultrastructural evidence of synaptic contacts between substance P-, enkephalin-, and serotoninimmunoreactive terminals and retrogradely labeled sympathetic preganglionic neurons in the rat: a study using a double-peroxidase procedure. Synapse 6, 221-229.

Virtanen, K. A., Lidell, M. E., Orava, J., Heglind, M., Westergren, R., Niemi, T., Taittonen, M., Laine, J., Savisto, N. J., Enerback, S., and Nuutila, P. (2009). Functional brown adipose tissue in healthy adults. N. Engl. J. Med. 360, 1518-1525.

Yamagata, K., Matsumura, K., Inoue, W., Shiraki, T., Suzuki, K., Yasuda, S., Sugiura, H., Cao, C., Watanabe, Y., and Kobayashi, S. (2001). Coexpression of microsomaltype prostaglandin E synthase with cyclooxygenase-2 in brain endothelial cells of rats during endotoxin-induced fever. $J$ Neurosci. 21, 2669-2677.

Yoshida, K., Konishi, M., Nagashima, K., Saper, C. B., and Kanosue, K. (2005). Fos activation in hypothalamic neurons during cold or warm exposure: projections to periaqueductal gray matter. Neuroscience 133 , 1039-1046.

Yoshida, K., Li, X., Cano, G., Lazarus, M., and Saper, C. B. (2009). Parallel preoptic pathways for thermoregulation. J. Neurosci. 29, 11954-11964.

Yoshida, K., Nakamura, K., Matsumura, K., Kanosue, K., Konig, M., Thiel, H. J., Boldogkoi, Z., Toth, I., Roth, J., Gerstberger, R., and Hubschle, T. (2003). Neurons of the rat preoptic area and the raphe pallidus nucleus innervating the brown adipose tissue express the prostaglandin E receptor subtype EP3. Eur. J. Neurosci. 18, 1848-1860.

Yoshimatsu, H., Egawa, M., and Bray, G. A. (1993). Sympathetic nerve activity after discrete hypothalamic injections of L-glutamate. Brain Res. 601, 121-128.

Zaretskaia, M. V., Zaretsky, D. V., and Dimicco, J. A. (2003). Role of the dorsomedial hypothalamus in thermogenesis and tachycardia caused by microinjection of prostaglandin E2 into the preoptic area in anesthetized rats. Neurosci. Lett. 340, 1-4. Zaretskaia, M. V., Zaretsky, D. V. Shekhar, A., and Dimicco, J. A. (2002). Chemical stimulation of the dorsomedial hypothalamus evokes non-shivering thermogenesis in anesthetized rats. Brain Res. 928, 113-125.

Zaretsky, D. V., Hunt, J. L., Zaretskaia, M. V., and Dimicco, J. A. (2006) Microinjection of prostaglandin E2 and muscimol into the preoptic area in conscious rats: comparison of effects on plasma adrenocorticotrophic hormone (ACTH), body temperature, locomotor activity, and cardiovascular function. Neurosci. Lett. 397, 291-296.

Zaretsky, D. V., Zaretskaia, M. V., and Dimicco, J. A. (2003). Stimulation and blockade of GABAA receptors in the raphe pallidus: effects on body temperature, heart rate, and blood pressure in conscious rats. Am. J. Physiol. Regul. Integr. Comp. Physiol. 285, R110-R116.

Zhang, Y. H., Lu, J., Elmquist, J. K., and Saper, C. B. (2000). Lipopolysaccharide activates specific populations of hypothalamic and brainstem neurons that project to the spinal cord. J. Neurosci. 20, 6578-6586.

Conflict of Interest Statement: The authors declare that the research was conducted in the absence of any commercial or financial relationships that could be construed as a potential conflict of interest.

Received: 17 October 2011; paper pending published: 12 November 2011; accepted: 06 January 2012; published online: 24 January 2012.

Citation: Morrison SF, Madden CJ and Tupone D (2012) Central control of brown adipose tissue thermogenesis. Front. Endocrin. 3:5. doi: 10.3389/fendo.2012.00005

This article was submitted to Frontiers in Cellular Endocrinology, a specialty of Frontiers in Endocrinology.

Copyright (c) 2012 Morrison, Madden and Tupone. This is an open-access article distributed under the terms of the Creative Commons Attribution Non Commercial License, which permits noncommercial use, distribution, and reproduction in other forums, provided the original authors and source are credited. 